\title{
Histone H3K4 and H3K36 methylation promotes recruitment, but not activity, of the NuA3 histone acetyltransferase complex in S. cerevisiae
}

Benjamin J.E. Martin*, Kristina L. McBurney*, Vicki E. Maltby ††, Kristoffer N. Jensen†, Julie Brind'Amour' and LeAnn J. Howe*

*Department of Biochemistry and Molecular Biology and †Department of Medical Genetics, Life Sciences Institute, University of British Columbia, Vancouver, B.C., Canada, V6T $1 Z 3$

$\dagger †$ Hunter Medical Research Institute, and School of Biomedical Sciences and Pharmacy, University of Newcastle, Newcastle NSW, Australia, 2308. 
Running title: Targeting of NuA3 by histone methylation.

Keywords: Histone acetylation, histone methylation, NuA3, histone acetyltransferase, $S$. cerevisiae

Corresponding author: LeAnn Howe

Department of Biochemistry and Molecular Biology

University of British Columbia

2350 Health Sciences Mall Vancouver, B.C., Canada

V6T $1 Z 3$

Phone: (604) 822-6297

Email: ljhowe@mail.ubc.ca 


\section{Abstract}

Histone post-translational modifications (PTMs) alter chromatin structure by promoting the interaction of chromatin-modifying complexes with nucleosomes. The majority of chromatin-modifying complexes contain multiple domains that preferentially interact with modified histones, leading to speculation that these domains function in concert to target nucleosomes with distinct combinations of histone PTMs. In S. cerevisiae, the NuA3 histone acetyltransferase complex contains three domains, the PHD finger in Yng1, the PWWP domain in Pdp3, and the YEATS domain in Taf14, which in vitro bind to H3K4 methylation, H3K36 methylation, and acetylated and crotonylated H3K9 respectively. However the relative in vivo contributions of these histone PTMs in targeting NuA3 is unknown. Here we show that in vivo H4K4 and H3K36 methylation, but not acetylated or crotonylated H3K9, recruit NuA3 to transcribed genes. Through genome-wide colocalization and by mutational interrogation, we demonstrate that the PHD finger of Yng1, and the PWWP domain of Pdp3 independently target NuA3 to H3K4 and H3K36 methylated chromatin respectively. In contrast, we find no evidence to support the YEATS domain of Taf14 functioning in NuA3 recruitment. Collectively our results suggest that the presence of multiple histone-PTM binding domains within $\mathrm{NuA3}$, rather than restricting it to nucleosomes containing distinct combinations of histone PTMs, can serve to increase the range of nucleosomes bound by the complex. Interestingly however, the simple presence of NuA3 is insufficient to ensure acetylation of the 
bioRxiv preprint doi: https://doi.org/10.1101/096511; this version posted December 23, 2016. The copyright holder for this preprint (which was not certified by peer review) is the author/funder, who has granted bioRxiv a license to display the preprint in perpetuity. It is made available under aCC-BY 4.0 International license.

associated nucleosomes, suggesting a secondary level of acetylation regulation that does not involve control of HAT-nucleosome interactions 


\section{Introduction}

Eukaryotic DNA is packaged into a nucleoprotein structure known as chromatin, which consists of DNA, histones, and non-histone proteins. Histones are extensively post-translationally modified, with specific modifications reflecting activities occurring on the underlying DNA. For example, genes transcribed by RNA polymerase II (RNAPII) have acetylated and H3K4 tri-methylated histones (H3K4me3) at their 5' ends and H3K36 tri-methylated histones (H3K36me3) over the gene body (Pokholok et al. 2005; Liu et al. 2005). In contrast, histone H2A glutamine 105 methylation and H2A.X serine 139 phosphorylation are associated with RNA polymerase I transcription and DNA double strand break repair respectively (Rogakou et al. 1998; Tessarz et al. 2014). It is generally accepted that these modifications promote the biological processes to which they are associated.

Although some histone post-translational modifications (PTMs) can directly alter chromatin structure, most function as recognition sites for histone PTM binding domains (Yun et al. 2011). Histone PTM binding domains are found in complexes that facilitate transcription or alter chromatin structure, such as basal transcription factors, chromatin-remodeling complexes and even enzymes that post-translationally modify histones. The majority of chromatin-modifying complexes have multiple histone PTM binding domains, the purpose of which has been the subject of much speculation. The generally weak affinity of these domains for their requisite histone PTM has led to the hypothesis that multiple histonebinding interactions are required to stabilize the binding of complexes to chromatin (Yun et al. 2011). Indeed, it is suggested that multiple histone-binding domains 
function synergistically to translate "a code" of histone PTMs into a single biological outcome (Strahl and Allis 2000). Alternatively, multiple histone binding domains could act independently to target a chromatin-binding complex to a range of genomic loci.

One complex containing multiple histone PTM binding domains is the NuA3 histone acetyltransferase (HAT) complex in S. cerevisiae. NuA3 contains six subunits: including the catalytic subunit Sas3, Nto1, Eaf6 and three histone PTMbinding proteins: Yng1, Pdp3, and Taf14 (John et al. 2000; Howe et al. 2002; Taverna et al. 2006). Yng1 contains a PHD finger which binds to H3K4 mono-, diand trimethylation, with binding affinity increasing with the number of methyl groups. Pdp3 contains a PWWP domain, which recognizes H3K36me3. Taf14, through its YEATS domain, binds to acetylated (H3K9ac) and crotonylated (H3K9cr) histone H3K9. While the in vitro binding of these proteins to histone PTMs has been well characterized (Table S1), the relative contributions these histone PTMs make to NuA3 targeting in vivo remains unknown.

In mammalian cells, two HAT complexes appear analogous to NuA3: the MOZ/MORF complex and the HB01-BRPF1 complex. Both complexes contain BRPF1 (bromodomain PHD finger protein 1) or one of its paralogs, BRPF2 or 3 (Doyon et al. 2006; Lalonde et al. 2013). BRPF1/2/3 share sequence similarity with yNto1, but additionally contain carboxy-terminal, H3K36me3-specific PWWP domains (Vezzoli et al. 2010), and thus may serve the role of both yNto1 and yPdp3 in mammalian complexes. The MOZ/MORF complex also has an H3K4me2/3specific PHD finger in its subunit, ING5 (inhibitor of growth 5), while the HBO1- 
BRPF1 uses ING4 or ING5 to bind to H3K4me2/3 (Doyon et al. 2006; Lalonde et al. 2013). Finally, although the MOZ/MORF and HBO1-BRPF1 complexes lack a Taf14 equivalent, a bromodomain within BRPF1/2/3 and a double PHD finger in MOZ/MORF show specificity for acetylated histones (Laue et al. 2008; Qiu et al. 2012; Liu et al. 2012; Ali et al. 2012). Thus, the histone PTM binding domains in NuA3 are conserved in analogous complexes in other organisms, although the relative contribution that these domains make in targeting $\mathrm{NuA} 3$ has yet to be determined.

In this study we show that NuA3 is primarily targeted to mid-gene regions via interactions with H3K36me3 and H3K4me1/2/3, while H3K9ac and H3K9cr are unlikely to play a role in recruitment. Simultaneous disruption of H3K4 and H3K36 methylation abolishes NuA3 recruitment to actively transcribed genes. In contrast, disruption of H3K4 or H3K36 methylation singularly results in partial loss of NuA3 recruitment, suggesting that these PTMs recruit NuA3 independently and arguing against a synergistic effect. Finally, we show that NuA3 occupancy does not dictate histone acetylation indicating that controlled targeting is not the only mechanism for regulation of $\mathrm{NuA3}$ function.

\section{Materials and Methods}

Yeast strains, antibodies and plasmids: All strains used in this study were isogenic to S288C, and are listed in Table S2. All strains are available upon request. Yeast culture and genetic manipulations were performed using standard protocols. Genomic deletions were verified by PCR analysis and whole cell extracts were 
generated as previously described (Kushnirov 2000). The previously described kanMX-GAL1pr-flo8-HIS3 strains (Cheung et al. 2008) were generous gifts of Fred Winston.

Drug treatments: For H3K23ac ChIP-seq, bar1 $\Delta$ cells were arrested in G1 by 2.5 hour treatment with $5 \mu \mathrm{M} \alpha$-factor. Culture synchrony in G1 was confirmed by the appearance of "shmooing" cells, as seen under the microscope. TSA was added for 15 minutes at $25 \mu \mathrm{M}$, from 5 mM DMSO stock.

Chromatin immunoprecipitation with sequencing (ChIP-seq): The ChIP-seq protocol was based on that outlined in (Maltby et al. 2012). Following cell lysis, the chromatin pellets were re-suspended in $900 \mu$ of NP-S buffer $(0.5$ mM spermidine, 1 $\mathrm{mM} \beta$-ME, 0.075\% NP-40, $50 \mathrm{mM} \mathrm{NaCl}, 10 \mathrm{mM}$ Tris $\mathrm{pH}$ 7.4, $5 \mathrm{mM} \mathrm{MgCl}$, $1 \mathrm{mM}$ $\mathrm{CaCl} 2$ ) and digested with 400 units of microccocal nuclease at $37^{\circ} \mathrm{C}$ for 10 minutes to obtain predominantly mono-nucleosomal DNA. Reactions were stopped with the addition of $10 \mathrm{mM}$ EDTA and digested lysates were clarified by centrifugation at $9000 \mathrm{~g}$ for 5 minutes. To extract insoluble chromatin, pellets were re-suspended in $300 \mu \mathrm{l}$ of lysis buffer with $0.02 \%$ SDS, and sonicated in a Diagenode Bioruptor at high output for 30 seconds on/30 seconds off for a total of 4 minutes. Extracts were then re-clarified by centrifugation at $9000 \mathrm{~g}$ for 10 minutes, and the supernatant pooled with the pre-existing extract. The buffer composition of the lysate was adjusted to that of the original lysate buffer, and 10\% was set aside as input. The supernatant was pre-cleared by incubation with $100 \mu \mathrm{l}$ magnetic protein-G 
Dynabeads (Life Technologies) for 1 hour at $4^{\circ} \mathrm{C}$. Pre-cleared lysates were incubated with $5 \mu \mathrm{g}$ of $\alpha \mathrm{HA}$ (Roche, cat no. 12013819001), $\alpha$ H3K4me3 (Abcam, cat no. ab1012), or $\alpha$ H3K23ac (Active Motif, cat no. 39131) antibodies at $4{ }^{\circ} \mathrm{C}$ overnight. Immune complexes were precipitated by incubation with $100 \mu$ of magnetic protein-G Dynabeads for one hour at $4^{\circ} \mathrm{C}$. Beads were washed and the immunoprecipitated DNA subjected to Illumina HiSeq 2000 paired- end sequencing as described (Maltby et al. 2012). Reads were aligned to the S. cerevisiae genome (Saccer3 genome assembly) using BWA (Li and Durbin 2010). Average gene profiles were generated using the sitepro tool in the CEAS genome package (http://liulab.dfci.harvard.edu/CEAS/) and plotted using R. Values past the polyadenylation sequence (Park et al. 2014) were excluded from the average calculation, and the fraction of genes included in the average calculation at any given distance from the TSS shown. The sequencing data generated for this paper will be made available through the Gene Expression Omnibus (GEO) database, www.ncbi.nlm.nih.gov/geo.

Published datasets: The datasets for the co-occurring nucleosomes and for H3K4me3 in the H3K36R mutant (Sadeh et al. 2016) were downloaded from the SRA study SRP078243. Histone methylation and acetylation datasets from (Weiner et al. 2015) were downloaded from SRA study SRP048526. H3K9ac datasets from (Bonnet et al. 2014) were downloaded from SRA study SRP033513. The H3K4me3 dataset from (Maltby et al. 2012) was from our previous study. The fastq files were mapped to saccer3 using BWA (Li and Durbin 2010). The methylation data from 
(Schulze et al. 2011) was downloaded from www.yeastgenome.org as mapped MAT scores. The Yng1 data from (Taverna et al. 2006) was kindly provided by the authors as mapped intensity scores for IPs and inputs. The NET-seq data from (Churchman and Weissman 2011) was downloaded from SRA study SRP004431 and mapped to saccer3 using bowtie (Langmead et al. 2009). The processed data for Gcn5 from (Xue-Franzén et al. 2013) was downloaded from the GEO depository, series GSE36600. For average gene profiles, the +1 nucleosome was called using BEDTools (Quinlan and Hall 2010) as the closest consensus nucleosome position (Brogaard et al. 2012) to the TSS (Brogaard et al. 2012). Cell cycle regulated genes were identified by (Eser et al. 2014) and were excluded from analysis comparing G1-arrested and asynchronous datasets.

Nucleosome enrichments: For each dataset the average coverage over genome wide called nucleosome positions (Weiner et al. 2015) was calculated. When available the IPs were normalized to input files. Spearman correlation matrix was calculated in $\mathrm{R}$, considering all pairwise complete observations.

Gene peak enrichment: For each gene, $100 \mathrm{bp}$ windows were constructed in $5 \mathrm{bp}$ steps, from upstream edge of +1 NCP to the end of the polyadenylation site to a maxium of $3000 \mathrm{bp}$. The average signal (IP coverage for data from (Sadeh et al. 2016) and IP/input for all others) was calculated for each bin. The peak bin for each gene was calculated and location of peak enrichment. Boxplots for peak position were constructed for each of the indicated data tracks. 
Boxplots: Methylation enrichment defined as having an IP/input of greater than 1.5, and depletion corresponded to an IP/input of less than 0.75. Boxplots extend from the $1^{\text {st }}$ to $3^{\text {rd }}$ quartiles, with whiskers extending to 1.5 times the interquartile range or to the extreme of the data. Notches extend +/- 1/58 IQR /sqrt(n) and give an approximation of the $95 \%$ confidence interval for the difference in 2 medians.

\section{Chromatin immunoprecipitation with quantitative PCR (ChIP-QPCR) of Sas3:}

Cells were grown in $50 \mathrm{ml} \mathrm{YPD}$ to an OD600 of 0.8 and cross-linked with 1\% formaldehyde for 30 minutes at room temperature. The reaction was stopped by the addition of $125 \mathrm{mM}$ glycine, and incubated at room temperature for a further 15 minutes. Pellets were washed twice with cold PBS, resuspended in $600 \mu \mathrm{l}$ of lysis buffer (50 mM HEPES pH 7.5, 140 mM NaCl, 0.5 mM EDTA, 1\% triton X-100, 0.1\% sodium deoxycholate), and lysed mechanically by vortexing with glass beads for 25 minutes at $4^{\circ} \mathrm{C}$. The lysates were spun down by centrifugation at $15,000 \mathrm{~g}$ for 30 minutes, the supernatant was discarded and the pellet was washed and resuspended in $500 \mu \mathrm{L}$ lysis buffer. The resuspended pellets were sonicated at high output for 30 seconds on/30 seconds off for 30 minutes to obtain an average fragment length of $250 \mathrm{bp}$. A further $200 \mu \mathrm{l}$ of lysis buffer was added to each sample, and the lysates were clarified by centrifugation at 9,000g for 10 minutes. Ten percent of the lysate was reserved for input. Lysates were incubated with $1 \mu \mathrm{g}$ antiHA antibody (Roche, cat no. 12CA5) at $4^{\circ} \mathrm{C}$ overnight, followed by precipitation of immune complexes with $25 \mu$ protein G Dynabeads at $4^{\circ} \mathrm{C}$ for 1 hour. The DNA was 
eluted and processed as described previously (Maltby et al., 2012a) and qPCR was performed in technical triplicate using the primers listed in Table S3.

\section{Results}

\section{NuA3 is primarily bound to mid-gene regions of actively transcribed genes}

The NuA3 histone acetyltransferase complex contains three histone PTM binding domains: the Yng1 PHD finger, the Pdp3 PWWP domain, and the Taf14 YEATS domain, which show specificity for H3K4me1/2/3, H3K36me3 and H3K9ac/H3K9cr respectively (Table S1). To determine the relative contribution of each histone PTM in targeting the NuA3 complex, we reasoned that histone PTMs that promote the interaction of NuA3 with chromatin would co-localize with Sas3. To this end, we mapped NuA3-bound nucleosomes at high resolution in vivo using an MNase-based ChIP-seq approach, which has previously been used to map chromatin remodelers (Koerber et al. 2009; Floer et al. 2010; Yen et al. 2012; Ramachandran et al. 2015). We immunoprecipitated HA-tagged Sas3, in parallel with an untagged control, from crosslinked MNase-digested chromatin and performed paired-end sequencing. We could not detect any DNA in the untagged control mock IP, but nonetheless constructed a library and included the sample in the pool for sequencing. While sequencing of the Sas3 IP and inputs produced over 8 million DNA fragments, only 84,973 DNA fragments were recovered in the untagged control IP, confirming the specificity of our Sas3 ChIP-seq experiment.

We mapped the sequenced DNA fragments to the $S$. cerevisiae genome, aligned genes by the +1 nucleosome, and calculated the average profile for each 
sample (Figure 1A). Relative to the input Sas3 was enriched in the gene body, but not at the +1 nucleosome, and this enrichment was specific to the Sas3 IP and was not observed for the untagged control. We next compared Sas3 occupancy to a previously reported sonication-based mapping of Yng1 (Taverna et al. 2006). Unsurprisingly, Yng1 and Sas3 levels correlated positively genome-wide with a Spearman correlation coefficient of 0.48 (Figures 1B and S1). Additionally both of

the Yng1 and Sas3 input-normalized distributions peaked in enrichment $600 \mathrm{bp}$ to $800 \mathrm{bp}$ downstream of the +1 nucleosome (Figure 1C). Thus our mapping of Sas 3 agreed well with the previous mapping of Yng1, but the MNase-based approach increased the resolution of the assay, and we found that $\mathrm{NuA} 3$ was primarily recruited to 'mid-gene' regions containing the +5 to +7 NCPs (Figure $1 \mathrm{C}$ ). We also observed that Sas3 was enriched on long genes and modestly enriched on genes transcribed by RNAPII (Figure 1D, E, and S2), consistent with Sas3 recruitment to mid-gene regions of actively transcribed genes.

\section{NuA3 is associated with H3K4me3, H3K4me2, H3K4me1, and H3K36me3 \\ nucleosomes genome wide}

As domains within NuA3 have been reported to bind to H3K4me3, H3K4me2, H3K4me1, H3K36me3, H3K9ac, and H3K9cr in vitro (Table S1), we hypothesized that if these modifications recruit $\mathrm{NuA} 3$ to nucleosomes in vivo they will correlate positively with Sas3. To conduct this meta-analysis, we made use of published genome-wide studies of these histone PTMs to calculate nucleosome-based Spearman correlations with Sas3 and Yng1 (Figure 2A, Table S4). Since 
crotonylation has not been mapped in S. cerevisiae, but colocalizes with acetylation in mammalian cells (Sabari et al. 2015), we used H3K9ac as a proxy for H3K9cr. To our surprise, H3K9ac did not correlate with Sas3 or Yng1, which suggests that despite Taf14 binding in vitro, it does not function in NuA3 recruitment in vivo. Conversely, H3K36me3, H3K4me3, H3K4me2 and H3K4me1 all correlated positively with Sas3 and Yng1, supporting their role in NuA3-nucleosome binding in vivo. Furthermore co-occurring H3K4me3 and H3K36me3 nucleosomes, identified through sequential IPs (Sadeh et al. 2016), strongly correlated with Sas3 with Spearman correlation coefficients above 0.5 (Figure 2A, Table S4). The dual H3K4me3 and H3K36me3 methylated nucleosomes also specifically grouped with Sas3 and Yng1 following Hierarchical clustering, consistent with NuA3 binding to nucleosomes through the combined effects of H3K36me3 and H3K4 methylation.

Next, we compared the locations of peak enrichment for Sas3, Yng1, H3K36me3, and H3K4 methylation (Figure 2B). Sas3 and Yng1 had median peak enrichments at $750 \mathrm{bp}$ and $657 \mathrm{bp}$ downstream of the +1 dyad respectively, which was in between the peak enrichments for H3K4me3 and H3K36me3. Notably Yng1 and Sas3 peaked in enrichment slightly downstream of co-occurring H3K4me3 and H3K36me3, suggesting that H3K4me2 and H3K4me1 are also important for NuA3 targeting. Altogether the peak enrichments of Sas3 and Yng1 were consistent with NuA3 being primarily recruited to mid-gene regions through the combined effects of H3K36me3 and H3K4 mono, di, and trimethylation.

We next assessed Sas3 enrichment on nucleosomes containing H3K4me1/2/3 or H3K36me3 singularly or in combination (Figure 2C). In the 
absence of H3K36me3 or H3K4 methylation Sas3 was depleted from nucleosomes. Likewise nucleosomes solely enriched in H3K4me1 were also depleted in Sas3, albeit with the caveat that we only identified 90 such nucleosomes and these may represent noise within one of the datasets or be atypical cases in the genome. H3K4me2 enriched nucleosomes are in all but a handful of nucleosomes also enriched for $\mathrm{H} 3 \mathrm{~K} 4 \mathrm{me} 1$ or $\mathrm{H} 3 \mathrm{~K} 4 \mathrm{me} 3$, and we were unable to interrogate this modification in isolation. Nucleosomes enriched singularly with H3K36me3 or H3K4me3 were enriched for Sas3 to a similar extent, suggesting that each of these modifications recruit Sas3 to nucleosomes independently. Nucleosomes enriched with both H3K4me1 and H3K36me3 were enriched for Sas3 to a greater extent than H3K36me3 alone, suggesting that H3K4me1 does indeed function in Sas3 recruitment. Nucleosomes enriched for both H3K4me3 and H3K36me3 were enriched further still in Sas3 binding, consistent with NuA3 preferentially binding H3K4me3 over H3K4me1. We found similar results upon analysis of Yng1 (Figure S3). Altogether this analysis supports H3K36me3 and H3K4me1/2/3 functioning to recruit $\mathrm{NuA3}$ to chromatin in vivo.

\section{H3K4 and H3K36 methylation are necessary for Sas3 binding to active genes}

\section{through Pdp3 and Yng1 respectively}

The genome-wide analysis suggested that H3K4 and H3K36 methylation are the major mechanisms for recruiting NuA3 to chromatin, and we next sought to test this directly. H3K4 and H3K36 methylation are entirely dependent on the histone methyltransferases Set1 and Set2 respectively, so we performed ChIP-qPCR for Sas3 
in strains lacking the methyltransferases singularly and in combination. Mutation of either SET1 or SET2 individually resulted in a partial loss of Sas3 at LOS1, SEC15, NUP145, and RPS28A (Figure 3A). However Sas3 remained enriched over background at these four genes, and was also enriched relative to a repressed gene, PUT4. In contrast to the modest loss in the single mutants, the set $1 \Delta \operatorname{set} 2 \Delta$ double mutant reduced Sas3 recruitment to background levels, demonstrating that Set1 and Set2 are necessary for Sas3 recruitment to chromatin. Furthermore, the Set1dependence of Sas3 binding to the mid and 3' regions of LOS1, SEC15, and NUP145 occurred in regions depleted for H3K4me3 (Figure 3B) but enriched for H3K4me2 and H3K4me1 (Figure S4), which supports these modifications recruiting Sas3 in vivo. Set2-dependent binding of Sas3 occurred at regions containing H3K36me3 (Figure 3C), consistent with this PTM recruiting Sas3 in vivo. Additionally, from the single to double mutants, Sas3 displayed a stepwise reduction in binding, consistent with H3K36me3 and H3K4me1/2/3 recruiting Sas3 to chromatin in an independent and additive manner.

To test if Sas3 recruitment to chromatin was dependent on the NuA3 domains reported to bind histone methylation we performed ChIP-qPCR for Sas3 in yng $1 \Delta P H D, p d p 3 \Delta$, and yng $1 \Delta P H D p d p 3 \Delta$ strains (Figure 3D). The $p d p 3 \Delta$ mutant had a similar reduction in Sas3 binding as the $\operatorname{set} 2 \Delta$ mutant at all but one locus, and demonstrates for the first time that Pdp3 is necessary for NuA3 recruitment to chromatin in vivo. At RPS28A, disrupting H3K36 methylation causes a reduction in H3K4me3 (Figure S5), so the greater loss of Sas3 binding in the set2 $\Delta$ compared to the $p d p 3 \Delta$ mutant was likely an indirect effect. The yng $1 \Delta P H D$ mutation caused a 
reduction in Sas3 recruitment at 5', mid, and 3' regions, consistent with Yng1 targeting NuA3 to H3K4me3, H3K4me2, and H3K4me1. The yng1 $\triangle P H D$ pdp3A double mutant resulted in Sas3 recruitment comparable to the untagged control at all loci tested. Altogether our ChIP-qPCR results support the hypothesis that Sas3 binds to actively transcribed chromatin due to binding of H3K4me1/2/3 and H3K36me3 by the Yng1 PHD finger and the Pdp3 PWWP domain respectively.

\section{Sas3 occupancy does not dictate histone H3K23 acetylation}

Histone H3K14 and H3K23 acetylation localize to the 5' ends of genes, which is inconsistent with our demonstrated occupancy of Sas3 (Fig S6) (Weiner et al. 2015). One explanation for this discrepancy is the presence of the histone deacetylase complex (HDAC), Rpd3S, which deacetylates nucleosomes in the body of transcribed genes (Carrozza et al. 2005; Keogh et al. 2005; Joshi and Struhl 2005). To test whether HDAC inhibition could reveal acetylation in the bodies of genes, we performed ChIP-seq analysis for H3K23ac in cells treated with the HDAC inhibitor, trichostatin A (TSA) (Figure 4A). Following TSA treatment, H3K23ac spread further downstream of the TSS, but this PTM was still largely restricted to the 5' ends of genes contrary to NuA3 occupancy, which was found across the bodies of genes. Further, deletion of $S A S 3$ failed to suppress cryptic transcription initiation of a reporter construct in a strain lacking the TSA-sensitive HDAC, RPD3S (Figure 4B) (Cheung et al. 2008), again suggesting that Sas3 was not responsible for acetylation at downstream targets. 
A disconnect between Sas3 occupancy and H3K23ac levels is surprising as it is generally thought that histone acetylation is regulated through control of HAT targeting. To further confirm these observations, we assessed the relationship between Sas3 and H3K23ac at the +1 to +10 nucleosomes, and while we did observe a modest association between Sas3 occupancy and H3K23ac (Figure S7A), the predominant determinant of $\mathrm{H} 3 \mathrm{~K} 23 \mathrm{ac}$ was the nucleosome position relative to the TSS (Fig 4C). H3K23ac decreased into the gene body, and this was largely independent of Sas3 occupancy and was seen with or without TSA treatment. The H3 HAT, Gcn5, with Sas3, is necessary for global H3 acetylation (Maltby et al. 2012), and so we asked if Gcn5 occupancy (Xue-Franzén et al. 2013) could explain the disparity between Sas3 occupancy and H3K23ac. Similar to Sas3, Gcn5 displayed a subtle association with H3K23ac (Fig S7B), but again this was a modest effect compared to gene position (Figure 4D). We observed similar effects when selecting for nucleosomes enriched for one or both of Sas3 and Gcn5 (Fig S8). Thus the lack of association of Sas3 with H3K23ac cannot be explained by Gcn5 occupancy, and the similar lack of association of Gcn5 with H3K23ac suggests that regulating HAT activity post-recruitment may be a general phenomenon. Collectively these results indicate that while histone methylation promotes the association of Sas3 with chromatin in gene bodies, this does not necessarily result in histone acetylation.

\section{Discussion}

In this study we investigated the relative contributions of histone PTMs in targeting NuA3 to chromatin. Using both genome-wide and locus-specific 
approaches we showed that H3K36me3 and H3K4me1/2/3 both independently and additively promoted the association of Sas3 with chromatin. We provide the first in vivo evidence for Pdp3 recruiting NuA3 to H3K36 trimethylated chromatin and for Yng1 recruiting NuA3 to H3K4me2 and H3K4me1. The additive effects of H3K36me3 and H3K4me1/2/3 resulted in NuA3 being primarily recruited to the +5 to +7 nucleosomes, approximately $700 \mathrm{bp}$ into the gene. This is close to but slightly further into the gene body than where the mammalian homologue MOZ/MORF is predominantly found, approximately $400 \mathrm{bp}$ downstream of the TSS (Lalonde et al. 2013). This 5' shift in MOZ/MORF localization could be due to the mammalian complex's reduced affinity for H3K4me1 (Champagne et al. 2008) (Table S1) and H3K36me3 (Vezzoli et al. 2010; Wu et al. 2011) (Table S1), resulting in a much greater dependence on H3K4me2/3 for recruitment to chromatin. The differing methyl-histone binding properties of NuA3 and MOZ/MORF coincide with differing genome-wide localization of H3K4me1 and H3K36me3. With longer mammalian genes H3K36me3 can stretch more than $20 \mathrm{~kb}$ from the TSS, while H3K4me1 is associated with enhancers (Barski et al. 2007). Thus the reduction in binding affinity for H3K36me3 and H3K4me1 has maintained MOZ/MORF targeting close to but downstream of the TSS, which suggests a conserved function in this genomic region.

Unlike for histone methylation, we found no evidence to support a role for histone acetylation or crontylation in NuA3 recruitment. While we did not test the effect of loss of acetylation or Taf14 on NuA3 binding, the complete loss of Sas3 recruitment in the absence of $\mathrm{H} 3 \mathrm{~K} 4$ and $\mathrm{H} 3 \mathrm{~K} 36$ methylation demonstrated that the 
YEATS domain was not sufficient for NuA3 recruitment. While it is possible that this domain has no function in $\mathrm{NuA3}$, the retention of acetyl-binding domains in mammalian MOZ/MORF argues for a functional role. It is possible that binding to acetyl or crontyl lysines of the histone tail may regulate NuA3's activity, similar to the role of histone methylation in stimulating the activity of the Rpd3S deacetylase complex (Govind et al. 2010). Alternatively regulation could occur through binding to non-histone substrates. Indeed proteomic studies show that Nto1 and Taf14 both contain acetylated lysines (Henriksen et al. 2012), and so it is possible that the YEATS domain is binding to a modified lysine in the NuA3 complex. Such a role is seen for the Rsc4 bromodomain, which binds to an acetylated lysine in the complex to regulate its function (VanDemark et al. 2007; Choi et al. 2008).

Our results showed that Sas3 was localized across the body of transcribed genes, which is inconsistent with the predominantly TSS-proximal patterns of H3K14ac and K23ac (Weiner et al. 2015). This is unsurprising however as other studies have shown that HAT occupancy is a poor predictor of histone acetylation (Xue-Franzén et al. 2010; Rossetto et al. 2014). Instead, these results suggest that there is a level of regulation of histone acetylation that is independent of HAT recruitment. Molecular simulation studies predict histone tails to be tightly intertwined with nucleosomal DNA (Shaytan et al. 2016), and thus disruption of these interactions may be required for acetylation by available HATs. Interestingly, although RNAPII is also found across gene bodies, NETseq and PAR-CLIP experiments show that RNAPII struggles to transcribe through the 5' ends of genes (Churchman and Weissman 2011; Schaughency et al. 2014), where the majority of 
histone acetylation is found. Thus an attractive hypothesis is that histones are acetylated by available HATs in response to DNA unwrapping during slow RNAPII passage. Although other molecular mechanisms could explain our observations, our data underscores the fact that the presence of a histone PTM-binding domain within a chromatin-modifying complex does not ensure that the associated enzymatic activity will function on all nucleosomes with the requisite PTM.

\section{Acknowledgements}

This work was supported by a Discovery Grant from the Natural Sciences and Engineering Research Council (NSERC) and an operating grant from the Canadian Institutes of Health Research awarded to L.J.H. B.J.E.M. is a recipient of an NSERC CGS award, while V.E.M. was supported by a University of British Columbia Four Year Fellowship. We gratefully acknowledge Fred Winston for providing yeast strains and plasmids and Sean Taverna for sharing ChIP-chip data.

\section{References:}

Ali M., Yan K., Lalonde M.-E., Degerny C., Rothbart S. B., Strahl B. D., Côté J., Yang X.-J., Kutateladze T. G., 2012 Tandem PHD Fingers of MORF/MOZ Acetyltransferases Display Selectivity for Acetylated Histone H3 and Are Required for the Association with Chromatin. Journal of Molecular Biology 424: 328-338.

Barski A., Cuddapah S., Cui K., Roh T.-Y., Schones D. E., Wang Z., Wei G., Chepelev I., Zhao K., 2007 High-resolution profiling of histone methylations in the human genome. Cell 129: 823-837.

Bonnet J., Wang C.-Y., Baptista T., Vincent S. D., Hsiao W.-C., Stierle M., Kao C.-F., Tora L., Devys D., 2014 The SAGA coactivator complex acts on the whole transcribed genome and is required for RNA polymerase II transcription. Genes Dev. 28: 1999-2012.

Brogaard K., Xi L., Wang J.-P., Widom J., 2012 A map of nucleosome positions in yeast at base-pair resolution. Nature 486: 496-501. 
Carrozza M. J., Li B., Florens L., Suganuma T., Swanson S. K., Lee K. K., Shia W.-J., Anderson S., Yates J., Washburn M. P., Workman J. L., 2005 Histone H3 methylation by Set2 directs deacetylation of coding regions by Rpd3S to suppress spurious intragenic transcription. Cell 123: 581-592.

Champagne K. S., Saksouk N., Peña P. V., Johnson K., Ullah M., Yang X.-J., Côté J., Kutateladze T. G., 2008 The crystal structure of the ING5 PHD finger in complex with an H3K4me3 histone peptide. Proteins 72: 1371-1376.

Cheung V., Chua G., Batada N. N., Landry C. R., Michnick S. W., Hughes T. R., Winston F., 2008 Chromatin- and transcription-related factors repress transcription from within coding regions throughout the Saccharomyces cerevisiae genome. PLoS Biol 6: e277.

Choi J. K., Grimes D. E., Rowe K. M., Howe L. J., 2008 Acetylation of Rsc4p by Gcn5p is essential in the absence of histone H3 acetylation. Mol. Cell. Biol. 28: 69676972.

Churchman L. S., Weissman J. S., 2011 Nascent transcript sequencing visualizes transcription at nucleotide resolution. Nature 469: 368-373.

Doyon Y., Cayrou C., Ullah M., Landry A.-J., COtE V., Selleck W., Lane W. S., Tan S., Yang X.-J., Côté J., 2006 ING tumor suppressor proteins are critical regulators of chromatin acetylation required for genome expression and perpetuation. Molecular Cell 21: 51-64.

Eser P., Demel C., Maier K. C., Schwalb B., Pirkl N., Martin D. E., Cramer P., Tresch A., 2014 Periodic mRNA synthesis and degradation co-operate during cell cycle gene expression. Mol. Syst. Biol. 10: 717.

Floer M., Wang X., Prabhu V., Berrozpe G., Narayan S., Spagna D., Alvarez D., Kendall J., Krasnitz A., Stepansky A., Hicks J., Bryant G. O., Ptashne M., 2010 A RSC/nucleosome complex determines chromatin architecture and facilitates activator binding. Cell 141: 407-418.

Govind C. K., Qiu H., Ginsburg D. S., Ruan C., Hofmeyer K., Hu C., Swaminathan V., Workman J. L., Li B., Hinnebusch A. G., 2010 Phosphorylated Pol II CTD recruits multiple HDACs, including Rpd3C(S), for methylation-dependent deacetylation of ORF nucleosomes. Molecular Cell 39: 234-246.

Henriksen P., Wagner S. A., Weinert B. T., Sharma S., Bacinskaja G., Rehman M., Juffer A. H., Walther T. C., Lisby M., Choudhary C., 2012 Proteome-wide analysis of lysine acetylation suggests its broad regulatory scope in Saccharomyces cerevisiae. Mol. Cell Proteomics 11: 1510-1522.

Howe L., Kusch T., Muster N., Chaterji R., Yates J. R., Workman J. L., 2002 Yng1p modulates the activity of Sas3p as a component of the yeast NuA3 Hhistone 
acetyltransferase complex. Mol. Cell. Biol. 22: 5047-5053.

John S., Howe L., Tafrov S. T., Grant P. A., Sternglanz R., Workman J. L., 2000 The something about silencing protein, Sas3, is the catalytic subunit of NuA3, a yTAF(II)30-containing HAT complex that interacts with the Spt16 subunit of the yeast CP (Cdc68/Pob3)-FACT complex. Genes Dev. 14: 1196-1208.

Joshi A. A., Struhl K., 2005 Eaf3 chromodomain interaction with methylated H3-K36 links histone deacetylation to Pol II elongation. Molecular Cell 20: 971-978.

Keogh M.-C., Kurdistani S. K., Morris S. A., Ahn S. H., Podolny V., Collins S. R., Schuldiner M., Chin K., Punna T., Thompson N. J., Boone C., Emili A., Weissman J. S., Hughes T. R., Strahl B. D., Grunstein M., Greenblatt J. F., Buratowski S., Krogan N. J., 2005 Cotranscriptional set2 methylation of histone H3 lysine 36 recruits a repressive Rpd3 complex. Cell 123: 593-605.

Koerber R. T., Rhee H. S., Jiang C., Pugh B. F., 2009 Interaction of transcriptional regulators with specific nucleosomes across the Saccharomyces genome. Molecular Cell 35: 889-902.

Kushnirov V. V., 2000 Rapid and reliable protein extraction from yeast. Yeast 16: 857-860.

Lalonde M.-E., Avvakumov N., Glass K. C., Joncas F.-H., Saksouk N., Holliday M., Paquet E., Yan K., Tong Q., Klein B. J., Tan S., Yang X.-J., Kutateladze T. G., Côté J., 2013 Exchange of associated factors directs a switch in HBO1 acetyltransferase histone tail specificity. Genes Dev. 27: 2009-2024.

Langmead B., Trapnell C., Pop M., Salzberg S. L., 2009 Ultrafast and memory-efficient alignment of short DNA sequences to the human genome. Genome Biol. 10: R25.

Laue K., Daujat S., Crump J. G., Plaster N., Roehl H. H., Tubingen 2000 Screen Consortium, Kimmel C. B., Schneider R., Hammerschmidt M., 2008 The multidomain protein Brpf1 binds histones and is required for Hox gene expression and segmental identity. Development 135: 1935-1946.

Li H., Durbin R., 2010 Fast and accurate long-read alignment with Burrows-Wheeler transform. Bioinformatics 26: 589-595.

Liu C. L., Kaplan T., Kim M., Buratowski S., Schreiber S. L., Friedman N., Rando O. J., 2005 Single-nucleosome mapping of histone modifications in S. cerevisiae. PLoS Biol 3: e328.

Liu L., Qin S., Zhang J., Ji P., Shi Y., Wu J., 2012 Solution structure of an atypical PHD finger in BRPF2 and its interaction with DNA. J. Struct. Biol. 180: 165-173.

Maltby V. E., Martin B. J. E., Brind'Amour J., Chruscicki A. T., McBurney K. L., Schulze 
J. M., Johnson I. J., Hills M., Hentrich T., Kobor M. S., Lorincz M. C., Howe L. J., 2012 Histone H3K4 demethylation is negatively regulated by histone $\mathrm{H} 3$ acetylation in Saccharomyces cerevisiae. Proc. Natl. Acad. Sci. U.S.A. 109: 18505-18510.

Park D., Morris A. R., Battenhouse A., Iyer V. R., 2014 Simultaneous mapping of transcript ends at single-nucleotide resolution and identification of widespread promoter-associated non-coding RNA governed by TATA elements. Nucleic Acids Res. 42: 3736-3749.

Pokholok D. K., Harbison C. T., Levine S., Cole M., Hannett N. M., Lee T. I., Bell G. W., Walker K., Rolfe P. A., Herbolsheimer E., Zeitlinger J., Lewitter F., Gifford D. K., Young R. A., 2005 Genome-wide map of nucleosome acetylation and methylation in yeast. Cell 122: 517-527.

Qiu Y., Liu L., Zhao C., Han C., Li F., Zhang J., Wang Y., Li G., Mei Y., Wu M., Wu J., Shi Y., 2012 Combinatorial readout of unmodified H3R2 and acetylated H3K14 by the tandem PHD finger of MOZ reveals a regulatory mechanism for HOXA9 transcription. Genes Dev. 26: 1376-1391.

Quinlan A. R., Hall I. M., 2010 BEDTools: a flexible suite of utilities for comparing genomic features. Bioinformatics 26: 841-842.

Ramachandran S., Zentner G. E., Henikoff S., 2015 Asymmetric nucleosomes flank promoters in the budding yeast genome. Genome Res. 25: 381-390.

Rogakou E. P., Pilch D. R., Orr A. H., Ivanova V. S., Bonner W. M., 1998 DNA doublestranded breaks induce histone H2AX phosphorylation on serine 139. J. Biol. Chem. 273: 5858-5868.

Rossetto D., Cramet M., Wang A. Y., Steunou A.-L., Lacoste N., Schulze J. M., COtE V., Monnet-Saksouk J., Piquet S., Nourani A., Kobor M. S., Côté J., 2014 Eaf5/7/3 form a functionally independent NuA4 submodule linked to RNA polymerase IIcoupled nucleosome recycling. EMBO J. 33: 1397-1415.

Sabari B. R., Tang Z., Huang H., Yong-Gonzalez V., Molina H., Kong H. E., Dai L., Shimada M., Cross J. R., Zhao Y., Roeder R. G., Allis C. D., 2015 Intracellular crotonyl-CoA stimulates transcription through p300-catalyzed histone crotonylation. Molecular Cell 58: 203-215.

Sadeh R., Launer-Wachs R., Wandel H., Rahat A., Friedman N., 2016 Elucidating Combinatorial Chromatin States at Single-Nucleosome Resolution. Molecular Cell: 1-24.

Schaughency P., Merran J., Corden J. L., 2014 Genome-wide mapping of yeast RNA polymerase II termination. PLoS Genet 10: e1004632.

Schulze J. M., Hentrich T., Nakanishi S., Gupta A., Emberly E., Shilatifard A., Kobor M. 
S., 2011 Splitting the task: Ubp8 and Ubp10 deubiquitinate different cellular pools of H2BK123. Genes Dev. 25: 2242-2247.

Shaytan A. K., Armeev G. A., Goncearenco A., Zhurkin V. B., Landsman D., Panchenko A. R., 2016 Coupling between Histone Conformations and DNA Geometry in Nucleosomes on a Microsecond Timescale: Atomistic Insights into Nucleosome Functions. Journal of Molecular Biology 428: 221-237.

Strahl B. D., Allis C. D., 2000 The language of covalent histone modifications. Nature 403: 41-45.

Taverna S. D., Ilin S., Rogers R. S., Tanny J. C., Lavender H., Li H., Baker L., Boyle J., Blair L. P., Chait B. T., Patel D. J., Aitchison J. D., Tackett A. J., Allis C. D., 2006 Yng1 PHD finger binding to $\mathrm{H} 3$ trimethylated at K4 promotes NuA3 HAT activity at K14 of H3 and transcription at a subset of targeted ORFs. Molecular Cell 24: 785-796.

Tessarz P., Santos-Rosa H., Robson S. C., Sylvestersen K. B., Nelson C. J., Nielsen M. L., Kouzarides T., 2014 Glutamine methylation in histone H2A is an RNApolymerase-I-dedicated modification. Nature 505: 564-568.

VanDemark A. P., Kasten M. M., Ferris E., Heroux A., Hill C. P., Cairns B. R., 2007 Autoregulation of the rsc 4 tandem bromodomain by gen5 acetylation. Molecular Cell 27: 817-828.

Vezzoli A., Bonadies N., Allen M. D., Freund S. M. V., Santiveri C. M., Kvinlaug B. T., Huntly B. J. P., Göttgens B., Bycroft M., 2010 Molecular basis of histone H3K36me3 recognition by the PWWP domain of Brpf1. Nat. Struct. Mol. Biol. 17: 617-619.

Weiner A., Hsieh T.-H. S., Appleboim A., Chen H. V., Rahat A., Amit I., Rando O. J., Friedman N., 2015 High-resolution chromatin dynamics during a yeast stress response. Molecular Cell 58: 371-386.

Wu H., Zeng H., Lam R., Tempel W., Amaya M. F., Xu C., Dombrovski L., Qiu W., Wang Y., Min J., 2011 Structural and histone binding ability characterizations of human PWWP domains. PLoS ONE 6: e18919.

Xue-Franzén Y., Henriksson J., Bürglin T. R., Wright A. P. H., 2013 Distinct roles of the Gcn5 histone acetyltransferase revealed during transient stress-induced reprogramming of the genome. BMC Genomics 14: 479.

Xue-Franzén Y., Johnsson A., Brodin D., Henriksson J., Bürglin T. R., Wright A. P. H., 2010 Genome-wide characterisation of the Gcn5 histone acetyltransferase in budding yeast during stress adaptation reveals evolutionarily conserved and diverged roles. BMC Genomics 11: 200. 
Yen K., Vinayachandran V., Batta K., Koerber R. T., Pugh B. F., 2012 Genome-wide nucleosome specificity and directionality of chromatin remodelers. Cell 149: 1461-1473.

Yun M., Wu J., Workman J. L., Li B., 2011 Readers of histone modifications. Nature Publishing Group 21: 564-578.

\section{Figure Legends}

Figure 1: NuA3 is primarily bound to mid-gene regions of actively transcribed genes. A. The average sequence coverage relative to $4701+1$ nucleosomes for Sas3HA and untagged IPs and MNase inputs. B. Spearman correlation coefficients for input-normalized Sas3 and Yng1 genome-wide enrichments. C. Average enrichment for Yng1 and Sas3 relative to the +1 nucleosome. Signal represents the $\log _{2}$ (IP/input) and plotted as relative signal within each sample. D. Sas3 enrichment by gene length, with gene length defined as the distance from the +1 nuclesome to the polyadenylation site. E. Sas3 enrichment by quartiles of sense NET-seq (Churchman and Weissman 2011) signal for genes longer than 1500bp. Only genes longer than $1500 \mathrm{bp}$ were plotted to avoid gene length effects but results are similar when all genes analyzed (Figure S2). Except for gene length plot, all average plots only include data until the PAS, and the grey line represents the fraction of genes still being plotted.

Figure 2: NuA3 is associated with H3K4me3, H3K4me2, H3K4me1, and H3K36me3 nucleosomes genome wide. A. Spearman correlation matrix for Sas3, Yng1 and histone PTM enrichments at 66360 genome-wide nucleosome positions. The rows and columns were sorted by hierarchical clustering, and the clustering is represented by dendrogram. B. Gene peak enrichments relative to the +1 nucleosome dyad represented by boxplot for 4701 genes. C. Sas3 enrichment at nucleosome positioned enriched or depleted for H3K4me1/2/3 and H3K36me3.

Figure 3: H3K4 and H3K36 methylation are necessary for Sas3 binding to active genes through Pdp3 and Yng1 respectively. A,C. Sas3 ChIP-qPCR in indicated strains at LOS1, SEC15, NUP145, RPS28A, and PUT4. Primer positions on genes are indicated in schematic. B. H3K4me3 and H3K36me3 ChIP-qPCR in wild type cells. Values represent the mean of at least three independent replicates. Error bars represent the standard error of the mean.

Figure 4: Sas3 occupancy does not dictate histone H3K23 acetylation. A. The average enrichment relative to $4264+1$ nucleosomes for Sas3 and H3K23ac before 
and after 15 minute incubation with $25 \mu \mathrm{M}$ TSA. Cell cycle regulated genes were excluded from this plot. Each gene is only included in the average calculation until its polyadenylation signal. The fractions of genes still contributing to the average profile are represented by the gray line. B. Ten-fold serial dilutions of the indicated strains containing the kanMX-GAL1pr-flo8-HIS3 reporter were plated on rich media (YPD) and complete synthetic media lacking histidine, and incubated at $30^{\circ} \mathrm{C}$ for four days. C,D. HAT and H3K23ac before and after TSA enrichments by nucleosome position and by Sas3 (C) or Gcn5 (Xue-Franzén et al. 2013) (D) quartiles, represented as boxplots. Nucleosomes from cell-cycle regulated genes were excluded, leaving 33942 nucleosomes from +1 to +10 positions relative to the TSS. Outliers were not plotted 
A

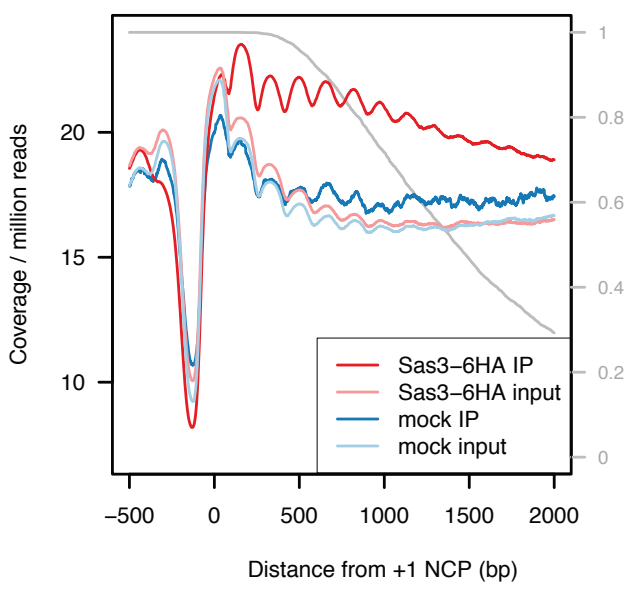

$\mathrm{D}$

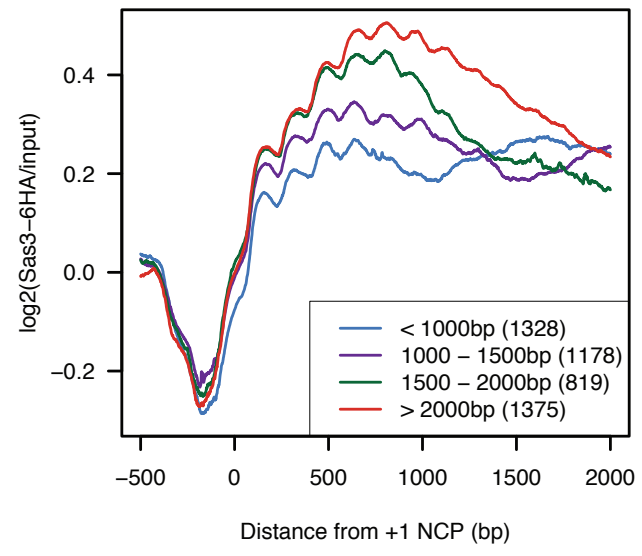

B

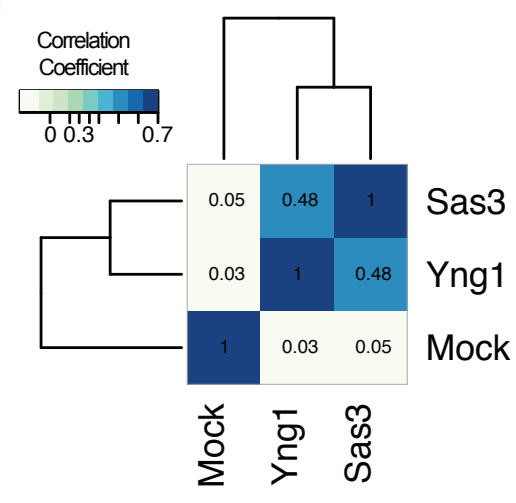

NET-seq quartiles

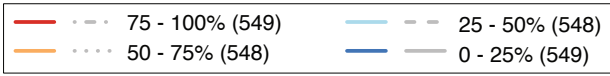
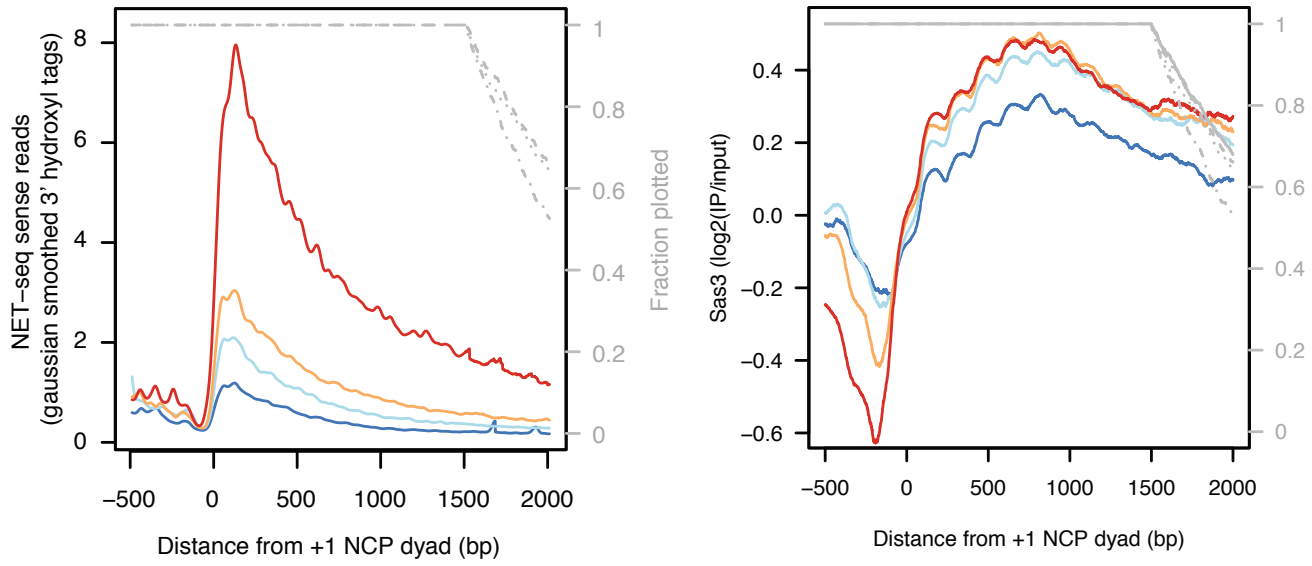


\section{A Spearman Coefficient}

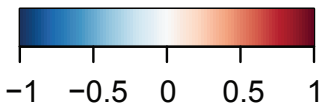

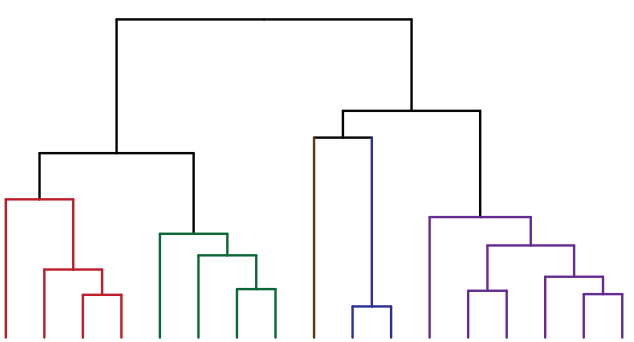

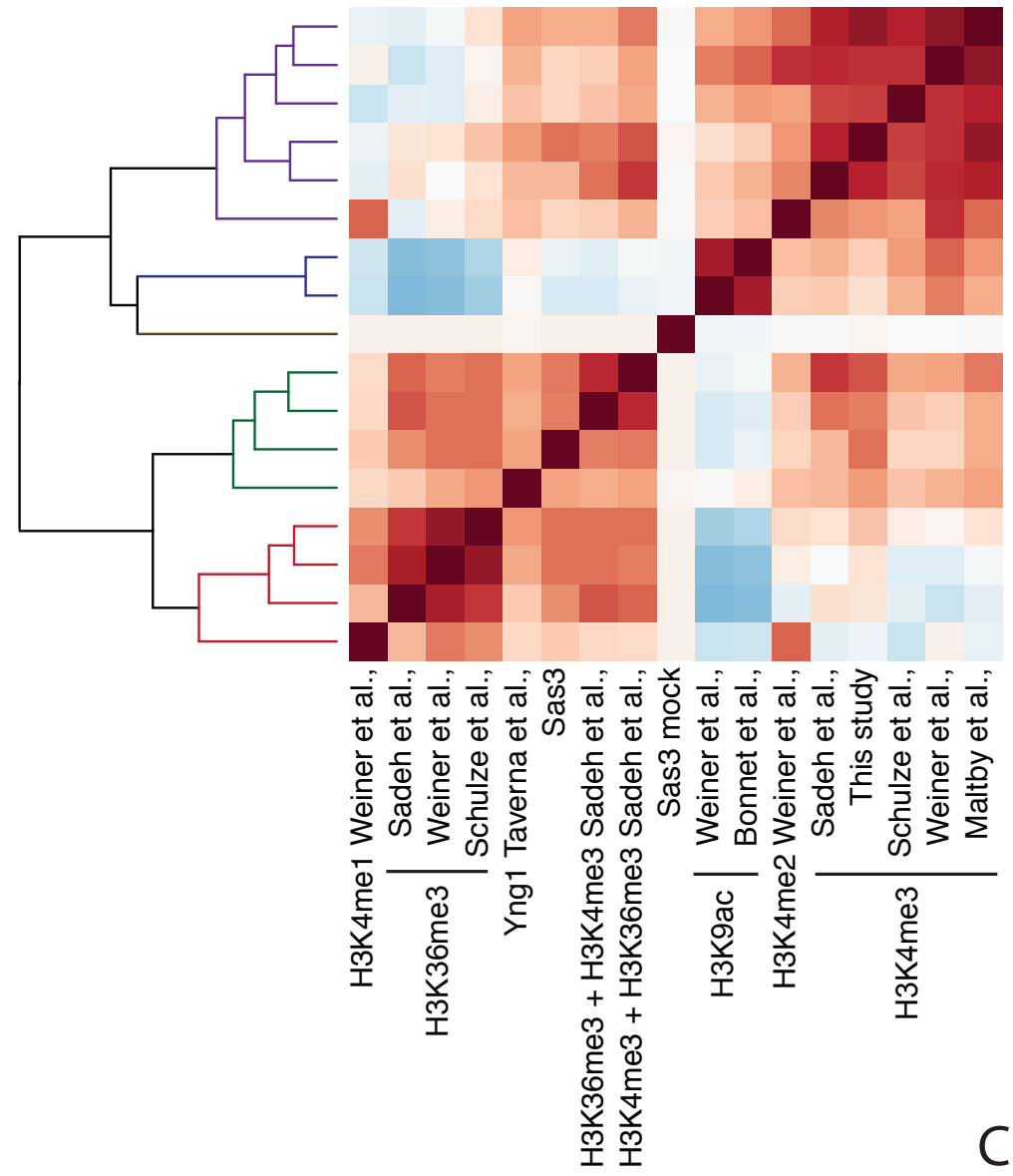

B

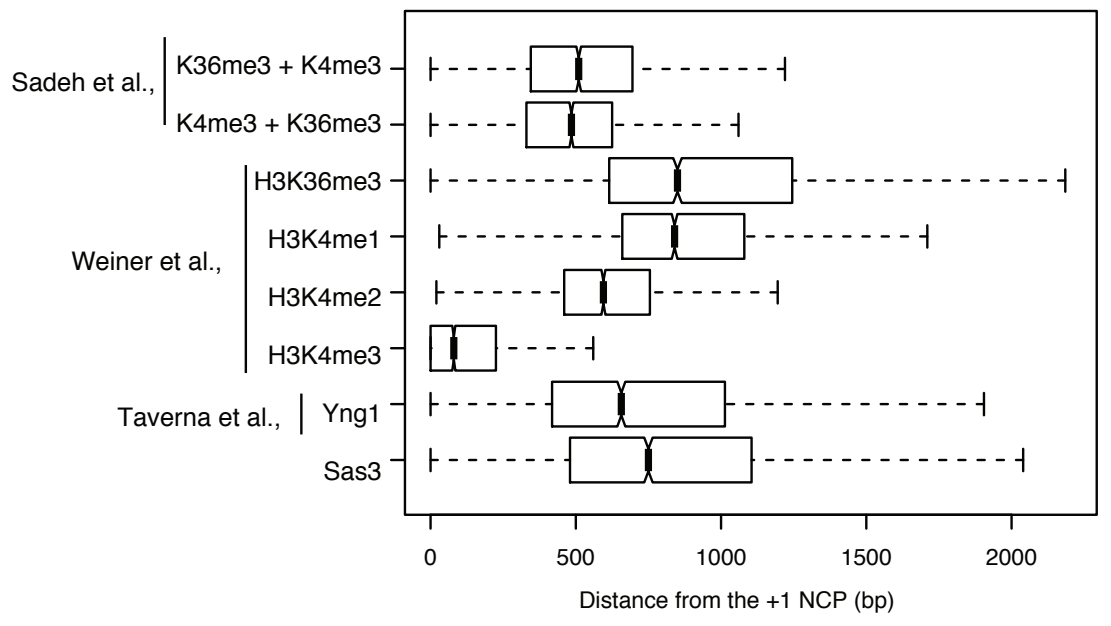

Figure 2

Maltby et al.,

Weiner et al.,

Schulze et al., H3K4me3

This study

Sadeh et al.,

H3K4me2 Weiner et al.,

\begin{tabular}{l|l} 
Bonnet et al., & H3K9ac \\
Weiner et al., &
\end{tabular}

Sas3 mock

H3K4me3 + H3K36me3 Sadeh et al.,

H3K36me3 + H3K4me3 Sadeh et al.,

Sas3

Yng1 Taverna et al.,

Schulze et al.,

Weiner et al., H3K36me3

Sadeh et al.,

H3K4me1 Weiner et al.,

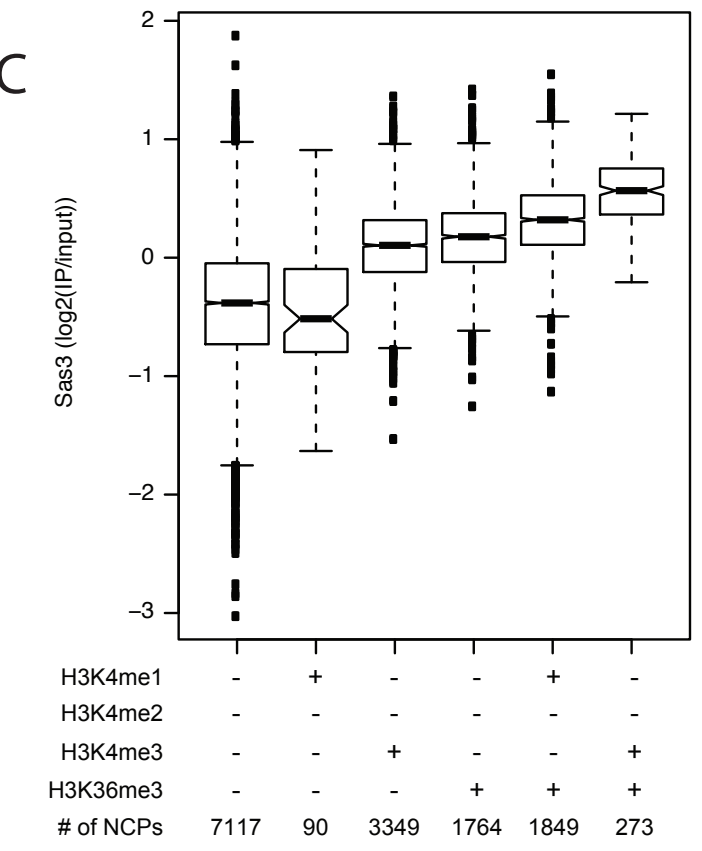


Figure 3

A

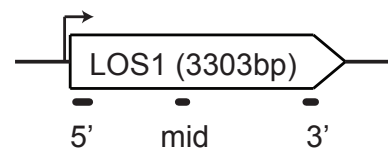

LOS1

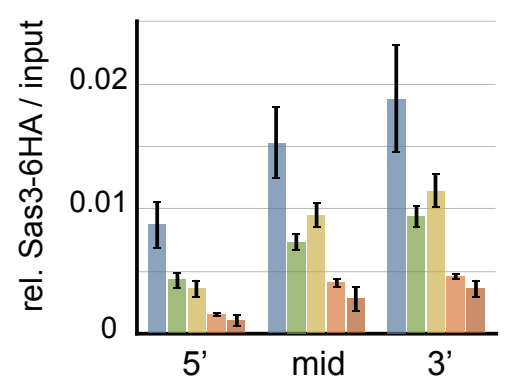

B

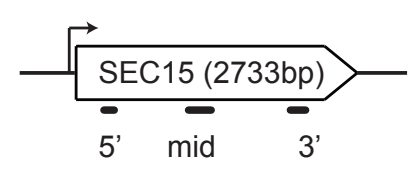

SEC15

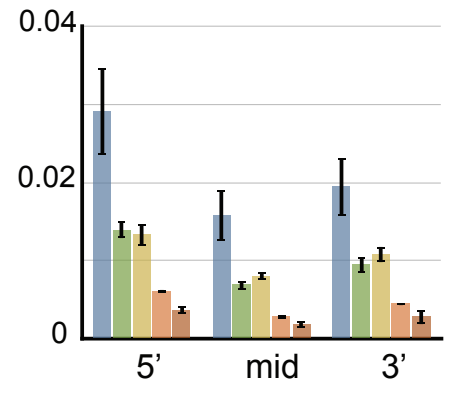

NUP145

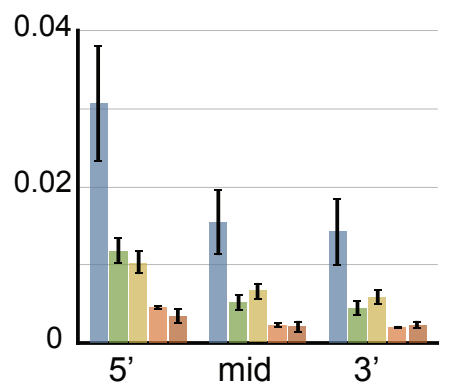

\section{RPS28A (203bp)}

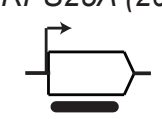

\section{Wildtype $\quad \operatorname{set} 2 \Delta \square \operatorname{set} 1 \Delta \square \operatorname{set} 1 \Delta \operatorname{set} 2 \Delta \square$ untagged}
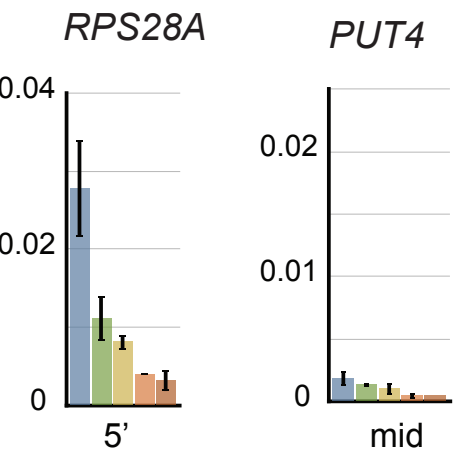

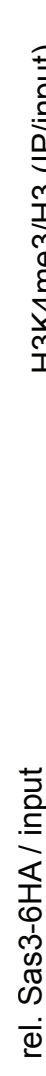

LOS1

D

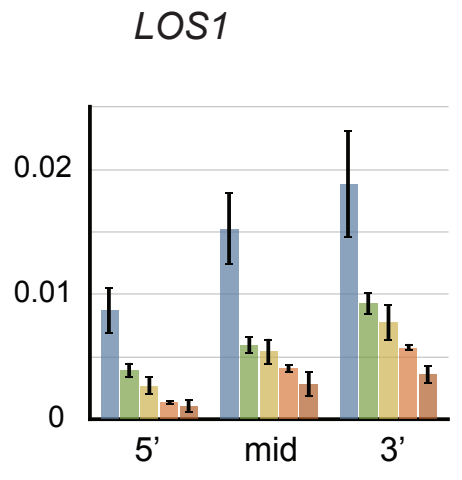

SEC15
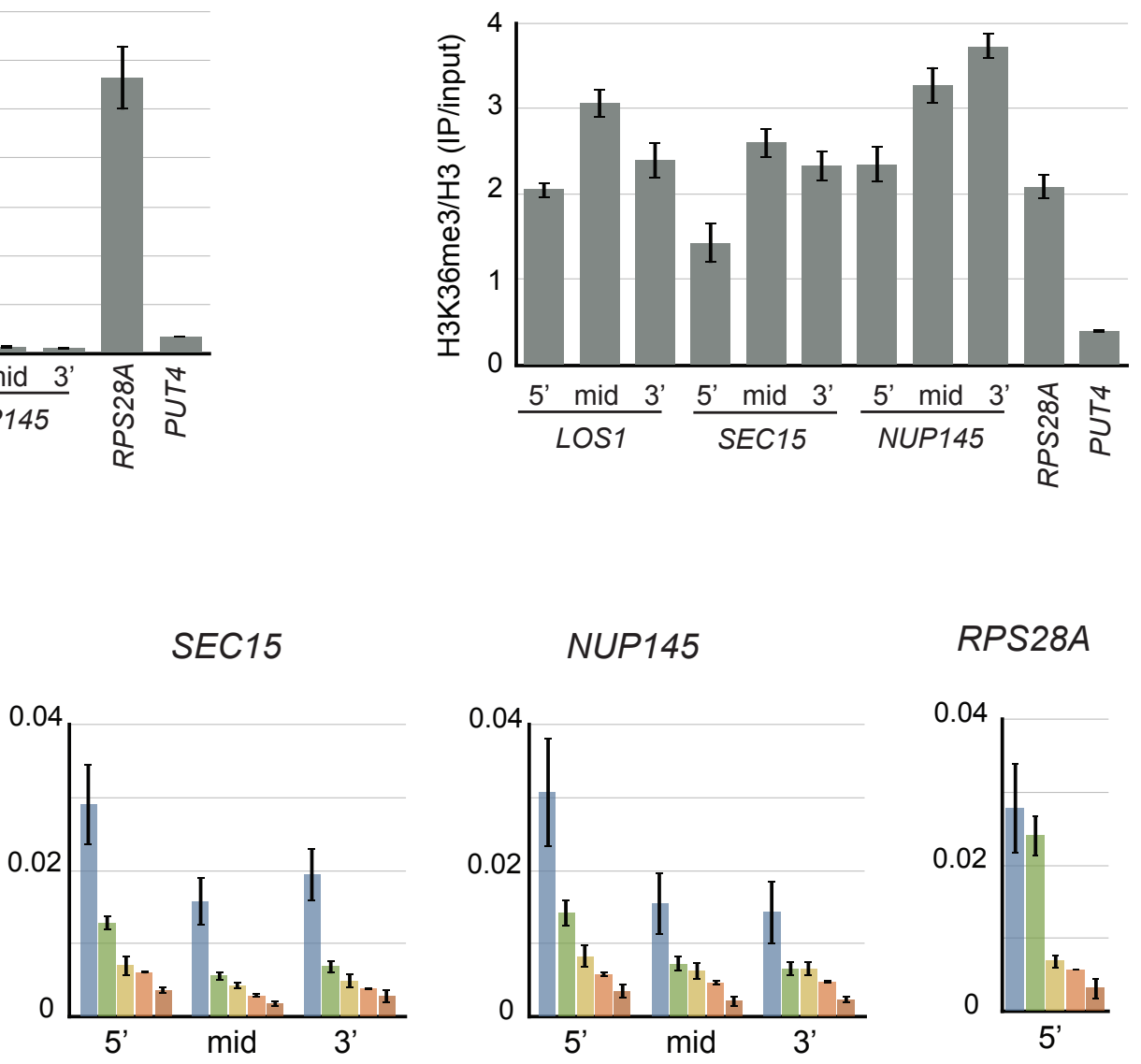

PUT4

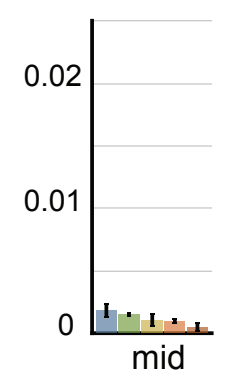

Wildtype $\square p d p 3 \Delta \square$ yng1 $1 \Delta P H \square$ yng1 $\triangle p d p 3 \Delta \square$ untagged 
bioRxiv preprint doi: https://doi.org/10.1101/096511; this version posted December 23, 2016. The copyright holder for this preprint (which was

not certified by peer review) is the author/funder, who has granted bioRxiv a license to display the preprint in perpetuity. It is made available under aCC-BY 4.0 International license.

A

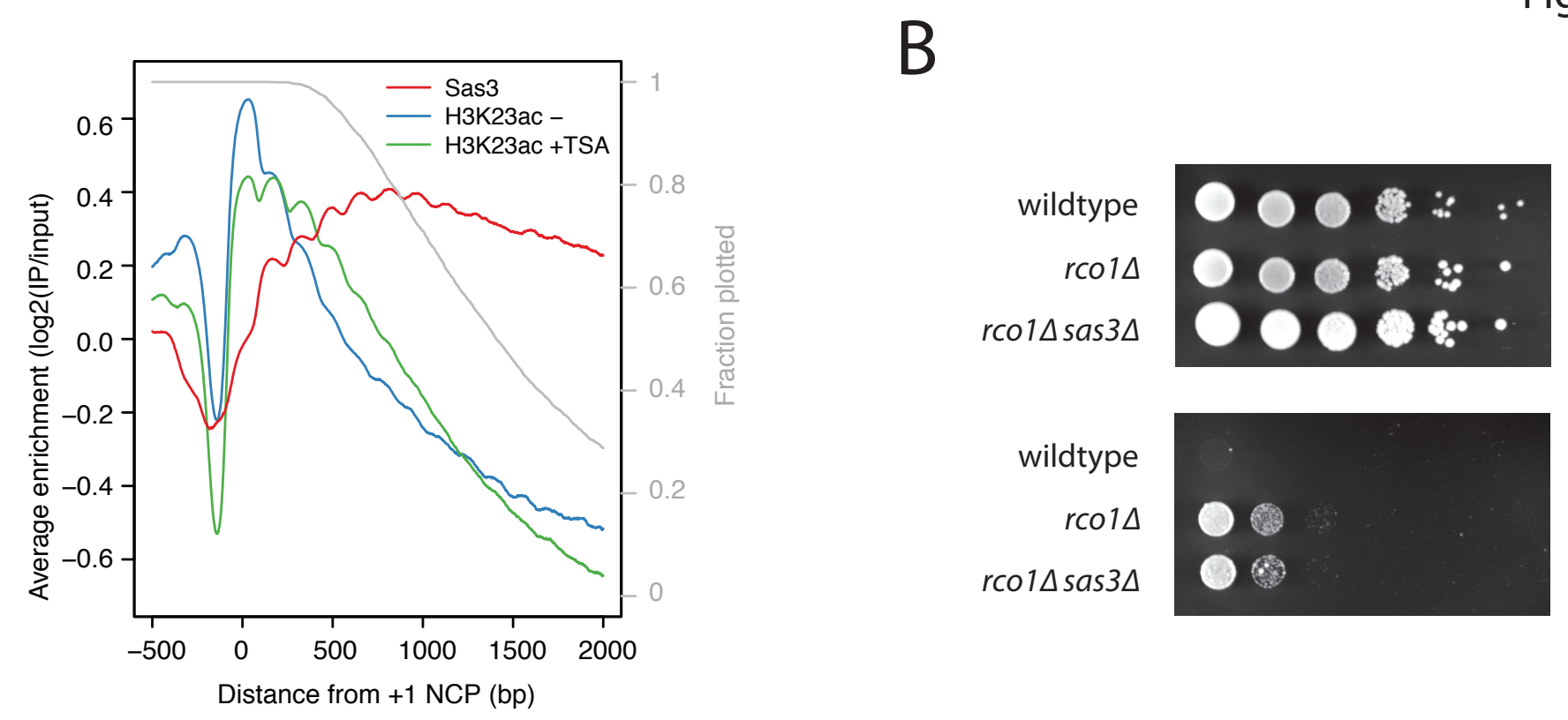

B

Figure 4

YPD
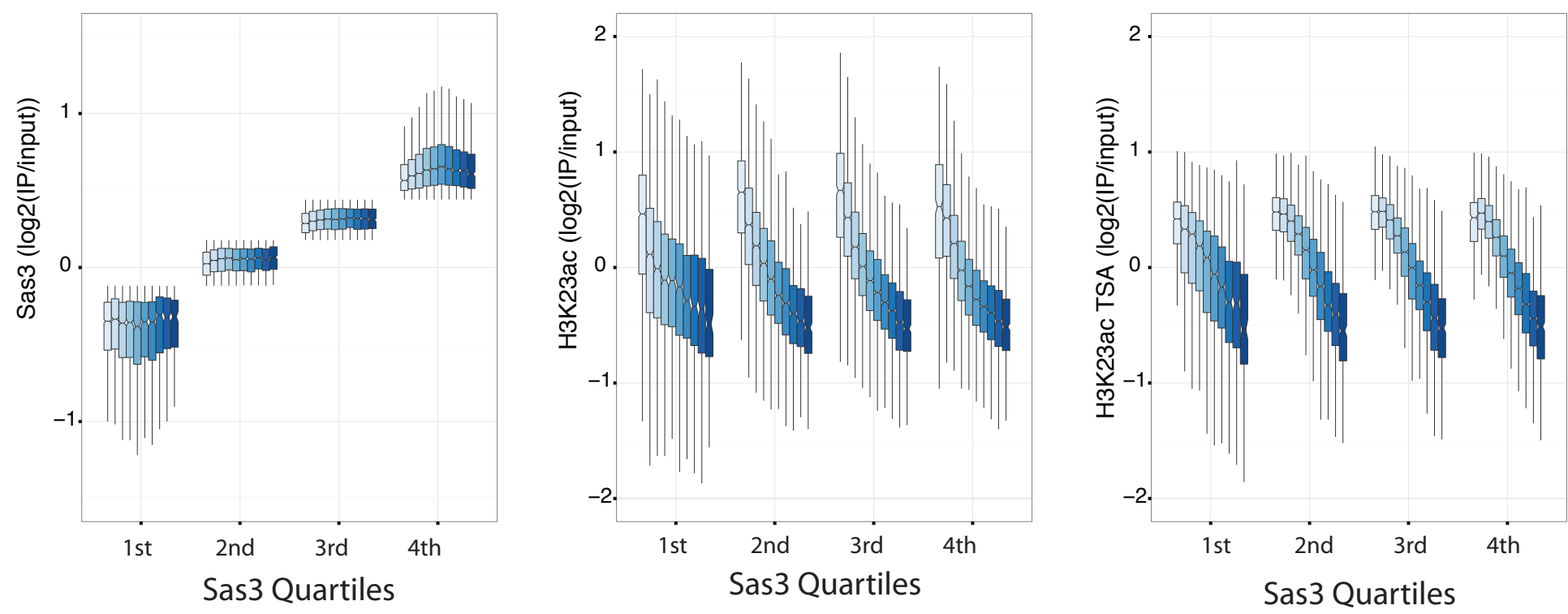

D
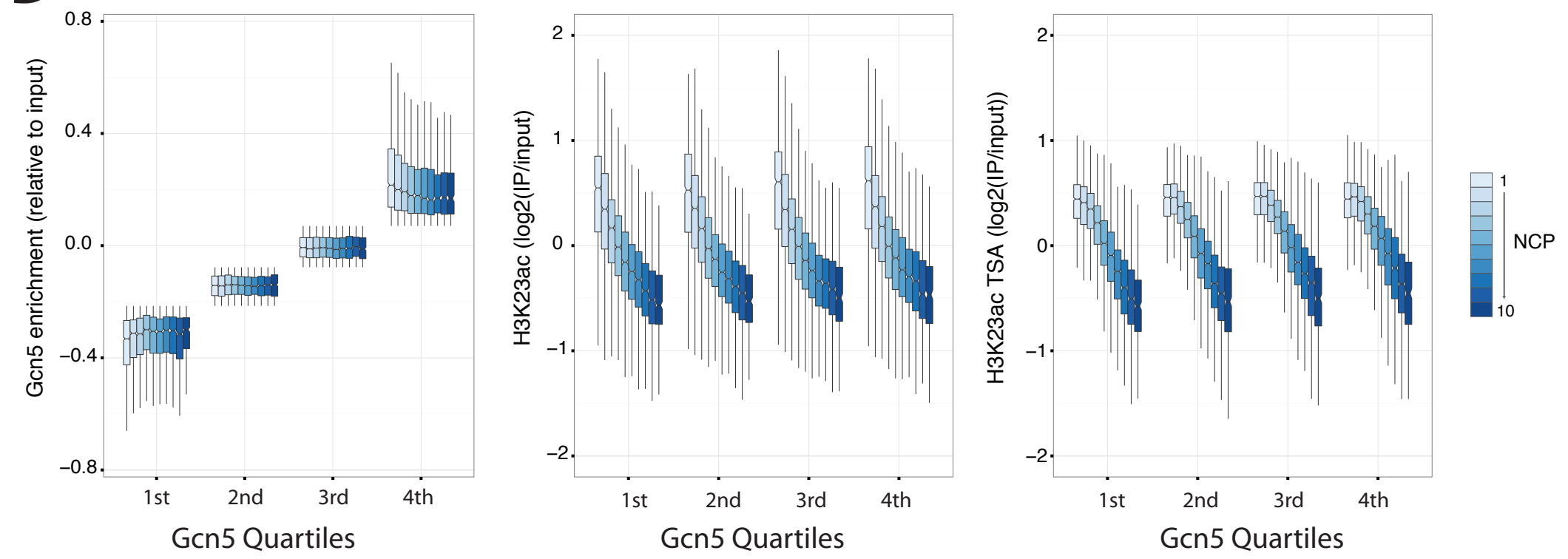


\section{Supplemental Figure Legends}

Figure S1: Sas3 and Yng1 colocalize genome wide. A. Scatter plot of Yng1 and Sas3 enrichment on $500 \mathrm{bp}$ windows, stepping in $250 \mathrm{bp}$ increments genome wide.

Figure S2. Sas3 is enriched on sense RNAPII-transcribed genes. A. Average profiles for NET-seq and Sas3 relative to the +1 nucleosome for genes split into quartiles of enrichment of NET-seq signal. Each gene is only included in the average calculation until its polyadenylation signal. The grey line represents the fraction of genes still contributing to the average profile.

Figure S3: Yng1 is enrichment at methylated nucleosomes. Yng1 enrichment at nucleosome positioned enriched or depleted for H3K4me1/2/3 and H3K36me3. Yng1 replicate is indicated by colour.

Figure S4: Histone methylation and Sas3 at candidate genes. Input-normalized Sas3 and histone methylation ChIP-seq coverage at LOS1, SEC15, NUP145, and PUT4 genes. ChIP-qPCR amplicons are indicated by red bars on schematic.

Figure S5: H3K4me3 decreases at RPS28A when H3K36 methylation is disrupted. H3K4me3 from wild type and H3K36R strains was quantitatively compared by competitive immunoprecipitation (data from Sadeh et al. 2016). The amount of H3K4me3 in wild type and H3K36R at 5' qPCR loci ( +100 bp on either side to account for change in resolution) was determined, and the change in methylation is plotted.

Figure S6: H3K14ac and H3K23ac are enriched 5' of Sas3. The average enrichment relative to $4701+1$ nucleosomes for Sas3, H3K14ac, and H3K23ac. $\mathrm{H} 3 \mathrm{~K} 14 \mathrm{ac}$ and H3K23ac data is from (Weiner et al. 2015). Each gene is only included in the average calculation until its polyadenylation signal. The fractions of genes still contributing to the average profile are represented by the gray line.

Figure S7: Modest association between Gcn 5 or Sas3 and H3K23ac. HAT and H3K23ac before and after TSA enrichments by Sas3 (A) or Gcn5 (B) quartiles and by $\mathrm{NCP}$, represented as boxplots. Nucleosomes from cell-cycle regulated genes were excluded, leaving 33942 nucleosomes from +1 to +10 positions relative to the TSS. Outliers were not plotted.

Figure S8: Gcn5 and Sas3 enrichment together does not dictate H3K23ac. Nucleosomes were classified as being enriched or depleted based on being the top or bottom quartile of HAT occupancy respectively. Nucleosomes were grouped as being depleted or enriched for both of Gcn5 or Sas3, enriched for one but not the other, and for not being in one of the above categories. Sas3, Gcn5, and H3K23ac before and after TSA treatment enrichments for each category were visualized by boxplot. Outliers were not plotted. 
Table S1: Published in vitro dissociation constants for NuA3 and MOZ/MORF histone-PTM binding domains.

Table S2: Strains

Table S3: ChIP-qPCR primers

Table S4: Nucleosome Spearman correlation coefficients. 
Table S1: Published in vitro dissociation constants for NuA3 and MOZ/MORF histone-PTM binding domains.

\begin{tabular}{|c|c|c|c|}
\hline Domain & Peptide & $K_{D}(\mu \mathrm{M})$ & Reference \\
\hline \multirow{4}{*}{ Yng1 PHD finger } & H3K4me3 & $\begin{array}{l}2.3+/-0.9 \\
9.1+/-1.6 \\
\end{array}$ & $\begin{array}{c}\text { (Shi et al. 2007), } \\
\text { (Taverna et al. 2006) }\end{array}$ \\
\hline & H3K4me2 & $21.4+/-3.0$ & (Taverna et al. 2006) \\
\hline & H3K4me1 & $50.7+/-7.6$ & (Taverna et al. 2006) \\
\hline & $\mathrm{H} 3 \mathrm{~K} 4 \mathrm{meO}$ & $>400$ & (Taverna et al. 2006) \\
\hline \multirow{6}{*}{ Pdp3 PWWP } & H3K36me3 & $69.5+/-3.7$ & (Gilbert et al. 2014) \\
\hline & H3K36me2 & $414+/-23$ & (Gilbert et al. 2014) \\
\hline & H3K36me1 & $>1000$ & (Gilbert et al. 2014) \\
\hline & $\mathrm{H} 3 \mathrm{~K} 36 \mathrm{meO}$ & $>1000$ & (Gilbert et al. 2014) \\
\hline & H3K79me3 & $434+/-49$ & (Gilbert et al. 2014) \\
\hline & H4K20me3 & $>1000$ & (Gilbert et al. 2014) \\
\hline \multirow{3}{*}{ Taf14 YEATS } & H3К9ас & $150.6+/-14.5$ & (Shanle et al. 2015) \\
\hline & H3К9,14,18ас & $49.9+/-2$ & (Shanle et al. 2015) \\
\hline & $\mathrm{H} 3 \mathrm{~K} 9 \mathrm{cr}$ & $9.5+/-0.5$ & (Andrews et al. 2016) \\
\hline \multirow{4}{*}{ ING5 PHD finger } & H3K4me3 & $2.4+/-1.0$ & (Champagne et al. 2008) \\
\hline & H3K4me2 & $16+/-1.2$ & (Champagne et al. 2008) \\
\hline & H3K4me1 & $222+/-17$ & (Champagne et al. 2008) \\
\hline & $\mathrm{H} 3 \mathrm{~K} 4 \mathrm{meO}$ & $261+/-34$ & (Champagne et al. 2008) \\
\hline \multirow{6}{*}{ BRPF1 PWWP } & H3K36me3 & $\begin{array}{c}2700+/-200 \\
2900-4000\end{array}$ & $\begin{array}{c}\text { (Vezzoli et al. 2010), } \\
\text { (Wu et al. 2011) }\end{array}$ \\
\hline & H3K36me2 & very weak & (Wu et al. 2011) \\
\hline & $\mathrm{H} 3 \mathrm{~K} 36 \mathrm{meO}$ & NB & (Wu et al. 2011) \\
\hline & H3K4me3 & NB & (Wu et al. 2011) \\
\hline & H3K79me3 & very weak & (Wu et al. 2011) \\
\hline & H3K9me3 & NB & (Wu et al. 2011) \\
\hline
\end{tabular}


Table S2: Strains

\begin{tabular}{|c|c|c|c|c|}
\hline Strain & Parent & $\begin{array}{c}\text { Mating } \\
\text { type }\end{array}$ & Genotype & Source \\
\hline YLH101 & FY602 & Mat a & his3D200 leu2D1 lys2-128d ura3-52 trp1D63 & \\
\hline YVM138 & YLH101 & Mat a & $\begin{array}{l}\text { his3D200 leu2D1 lys2-128d ura3-52 trp1D63 } \\
\text { SAS3-6HA::TRP }\end{array}$ & \\
\hline YVM142 & $\begin{array}{l}\text { YLR008 x } \\
\text { YLH354 }\end{array}$ & Mat a & $\begin{array}{l}\text { his3D200 leu2D1 lys2-128d ura3-52 trp1D63 } \\
\text { SAS3-6HA::HIS set1 } \triangle: \text { KANMX6 set2 } 2:: T R P\end{array}$ & \\
\hline YVM147 & YVM144 & Mat a & $\begin{array}{l}\text { his3D200 leu2D1 lys2-128d ura3-52 trp1D63 } \\
\text { SAS3-6HA::TRP yng1 } P \text { PHD::KANMX6 }\end{array}$ & \\
\hline YVM157 & YVM146 & Mat a & $\begin{array}{l}\text { his3D200 leu2D1 lys2-128d ura3-52 trp1D63 } \\
\text { SAS3-6HA::TRP set14::HISMX6 }\end{array}$ & \\
\hline YVM158 & YVM146 & Mat a & $\begin{array}{l}\text { his3D200 leu2D1 lys2-128d ura3-52 trp1D63 } \\
\text { SAS3-6HA::TRP set2A::HISMX6 }\end{array}$ & \\
\hline YVM207 & YVM146 & Mat a & $\begin{array}{l}\text { his3D200 leu2D1 lys2-128d ura3-52 trp1D63 } \\
\text { SAS3-6HA::TRP ylr455w::HIS }\end{array}$ & \\
\hline YLH696 & YVM147 & Mat a & $\begin{array}{l}\text { his3D200 leu2D1 lys2-128d ura3-52 trp1D63 SAS3- } \\
\text { 6HA::TRP yng1DPHD::KANMX6 ylr455w::HISMX6 }\end{array}$ & \\
\hline YLH787 & YLH101 & Mat a & $\begin{array}{l}\text { his3D200 leu2D1 lys2-128d ura3-52 trp1D63 } \\
\text { bar1::KAN }\end{array}$ & \\
\hline FY2173 & & $M A T \alpha$ & $\begin{array}{l}\text { his3 } 4200 \text { leu2 } 11 \text { lys2-128 } \operatorname{trp} 1 \Delta 63 \text { ura3-52 } \\
\text { kanMX-GAL1pr-FLO8-HIS3 }\end{array}$ & $\begin{array}{l}\text { (Cheung et } \\
\text { al. 2008) }\end{array}$ \\
\hline L1106 & & Mat a & $\begin{array}{l}\text { his3 } \Delta 200 \text { ura3 } \Delta 0 \text { kanMX-GAL1pr-FLO8-HIS3 } \\
\text { rco1 } \Delta 0:: \text { kanMX }\end{array}$ & $\begin{array}{l}\text { (Cheung et } \\
\text { al. 2008) }\end{array}$ \\
\hline YLH510 & L1106 & Mat a & $\begin{array}{l}\text { his3 } \Delta 200 \text { ura3 } \Delta 0 \text { kanMX-GAL1pr-FLO8-HIS3 } \\
\text { rco1 } \Delta 0:: \text { kanMX sas3::URA3 }\end{array}$ & \\
\hline
\end{tabular}


Table S3: ChIP-qPCR primers

\begin{tabular}{|c|c|}
\hline qPCR primer & Sequence ( $5^{\prime}$ to $\left.3^{\prime}\right)$ \\
\hline NUP145 s+3214 & GTATCTTCTGCTGCCTTGTCATC \\
\hline NUP145 a+3335 & CGAAGGAAACTAGCGATGAGG \\
\hline NUP145 a+1611 & CATTGGTTTGGTGGCTTCGTC \\
\hline NUP145 s+1488 & CAACATGATGTGGATCTCACAGC \\
\hline NUP145 a+281 & GTAGCGCCAAATAAGCCACC \\
\hline NUP145 s+148 & CTTCAACACCTAGCCCATCTGG \\
\hline SEC15 $a+2230$ & GACCCATGAATTGTCTCGTCAAGG \\
\hline SEC15 $s+2082$ & GTAAGGCAAGACCCGGATATCTC \\
\hline SEC15 $a+1312$ & GTGACAACCTGTCCATGAGTC \\
\hline SEC15 $s+1092$ & GGTACAGGTACTACTCCTGGATC \\
\hline SEC15 a+370 & GCACCATACCTTGGATGTTTGC \\
\hline SEC15 $s+230$ & GGACCCCGTAATTGATGAATTGG \\
\hline LOS1 $a+1395$ & CAGACTTGGGTCAATTACCACG \\
\hline LOS1 $a+2940$ & GTCGTCATTATCCAAGCAGGTCC \\
\hline LOS1 s+2831 & CTATACGCCGCAAGAGATCCAG \\
\hline LOS1 s+1301 & GGTCACACAGGATGATTTTGAGG \\
\hline LOS1 $a+230$ & CCATTTGGATTAGCGTTCACGC \\
\hline LOS1 s+69 & CAAGCCATCGAGCTGCTAAATG \\
\hline PUT4 a+714 & CACGCATAGAAAGATCGTGATCC \\
\hline PUT4 s+546 & CTGGTCACTAGGTACGTTGAC \\
\hline RPS28A s + 15 & CCAGTCACTTTAGCCAAGGTC \\
\hline RPS28A a +191 & CGAGCTTCACGTTCAGATTCC \\
\hline
\end{tabular}

\section{Supplemental References:}

Andrews F. H., Shinsky S. A., Shanle E. K., Bridgers J. B., Gest A., Tsun I. K., Krajewski K., Shi X., Strahl B. D., Kutateladze T. G., 2016 The Taf14 YEATS domain is a reader of histone crotonylation. Nature Chemical Biology 12: 396-398.

Champagne K. S., Saksouk N., Peña P. V., Johnson K., Ullah M., Yang X.-J., Côté J., Kutateladze T. G., 2008 The crystal structure of the ING5 PHD finger in complex with an H3K4me3 histone peptide. Proteins 72: 1371-1376.

Cheung V., Chua G., Batada N. N., Landry C. R., Michnick S. W., Hughes T. R., Winston F., 2008 Chromatin- and transcription-related factors repress transcription from within coding regions throughout the Saccharomyces cerevisiae genome. PLoS Biol 6: e277.

Gilbert T. M., McDaniel S. L., Byrum S. D., Cades J. A., Dancy B. C. R., Wade H., Tackett 
A. J., Strahl B. D., Taverna S. D., 2014 A PWWP domain-containing protein targets the NuA3 acetyltransferase complex via histone $\mathrm{H} 3$ lysine 36 trimethylation to coordinate transcriptional elongation at coding regions. Mol. Cell Proteomics 13: 2883-2895.

Shanle E. K., Andrews F. H., Meriesh H., McDaniel S. L., Dronamraju R., DiFiore J. V., Jha D., Wozniak G. G., Bridgers J. B., Kerschner J. L., Krajewski K., Martín G. M., Morrison A. J., Kutateladze T. G., Strahl B. D., 2015 Association of Taf14 with acetylated histone $\mathrm{H} 3$ directs gene transcription and the DNA damage response. Genes Dev. 29: 1795-1800.

Shi X., Kachirskaia I., Walter K. L., Kuo J.-H. A., Lake A., Davrazou F., Chan S. M., Martin D. G. E., Fingerman I. M., Briggs S. D., Howe L., Utz P. J., Kutateladze T. G., Lugovskoy A. A., Bedford M. T., Gozani 0., 2007 Proteome-wide analysis in Saccharomyces cerevisiae identifies several PHD fingers as novel direct and selective binding modules of histone $\mathrm{H} 3$ methylated at either lysine 4 or lysine 36. J. Biol. Chem. 282: 2450-2455.

Taverna S. D., Ilin S., Rogers R. S., Tanny J. C., Lavender H., Li H., Baker L., Boyle J., Blair L. P., Chait B. T., Patel D. J., Aitchison J. D., Tackett A. J., Allis C. D., 2006 Yng1 PHD finger binding to $\mathrm{H} 3$ trimethylated at K4 promotes NuA3 HAT activity at K14 of H3 and transcription at a subset of targeted ORFs. Molecular Cell 24: 785-796.

Vezzoli A., Bonadies N., Allen M. D., Freund S. M. V., Santiveri C. M., Kvinlaug B. T., Huntly B. J. P., Göttgens B., Bycroft M., 2010 Molecular basis of histone H3K36me3 recognition by the PWWP domain of Brpf1. Nat. Struct. Mol. Biol. 17: 617-619.

Weiner A., Hsieh T.-H. S., Appleboim A., Chen H. V., Rahat A., Amit I., Rando O. J., Friedman N., 2015 High-resolution chromatin dynamics during a yeast stress response. Molecular Cell 58: 371-386.

Wu H., Zeng H., Lam R., Tempel W., Amaya M. F., Xu C., Dombrovski L., Qiu W., Wang Y., Min J., 2011 Structural and histone binding ability characterizations of human PWWP domains. PLoS ONE 6: e18919. 
bioRxiv preprint doi: https://doi.org/10.1101/096511; this version posted December 23, 2016. The copyright holder for this preprint (which was not certified by peer review) is the author/funder, who has granted bioRxiv a license to display the preprint in perpetuity. It is made available under ACC-BY 4.0 International license.

Figure S1

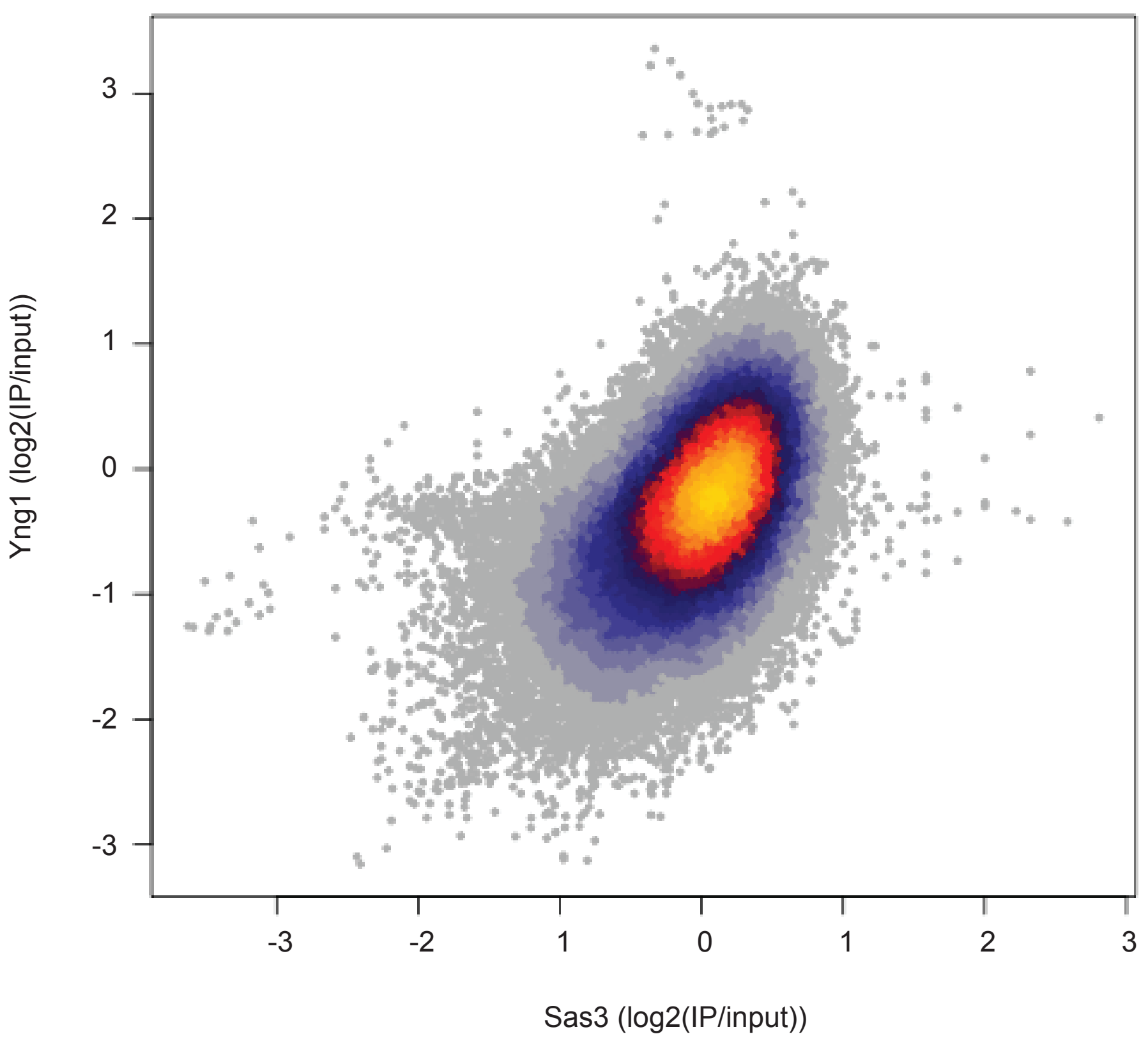


bioRxiv preprint doi: https://doi.org/10.1101/096511; this version posted December 23, 2016. The copyright holder for this preprint (which was not certified by peer review) is the author/funder, who has granted bioRxiv a license to display the preprint in perpetuity. It is made available under aCC-BY 4.0 International license.

Figure S2

\section{NET-seq quartiles}

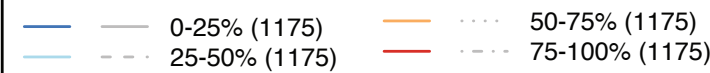
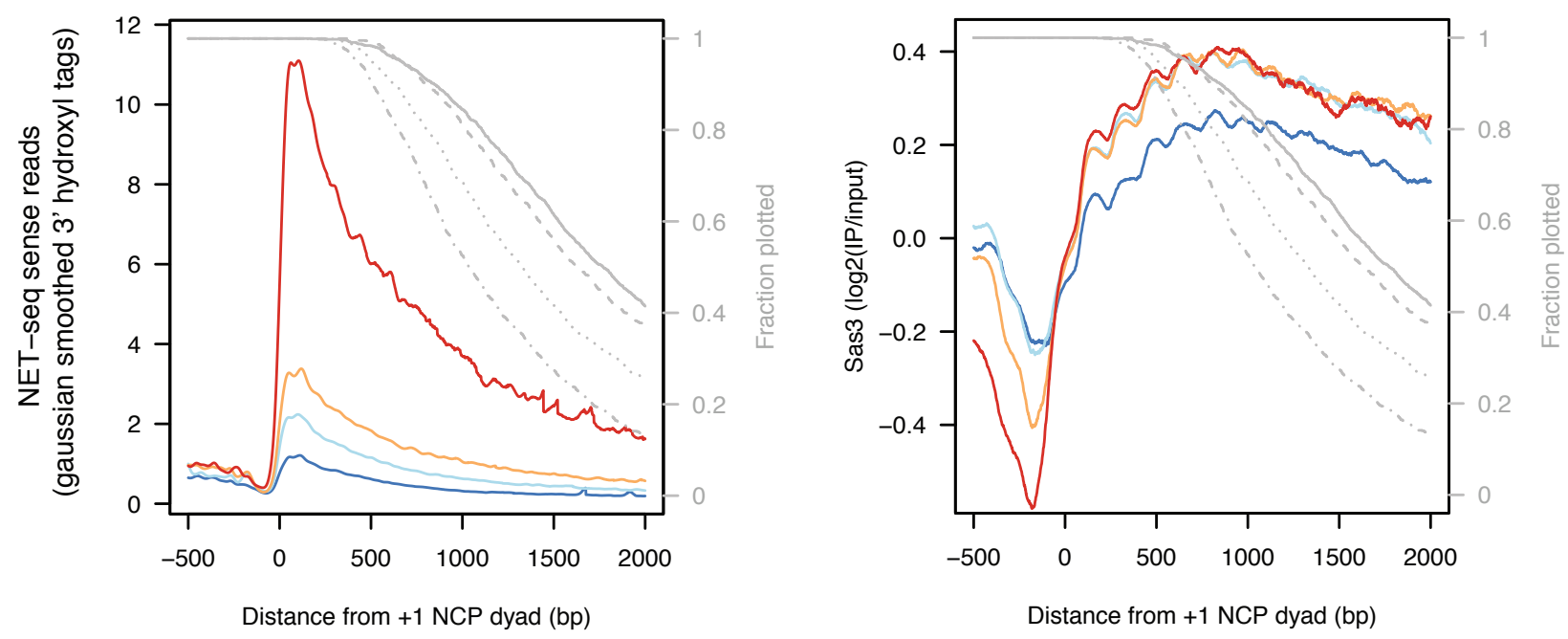
bioRxiv preprint doi: https://doi.org/10.1101/096511; this version posted December 23, 2016. The copyright holder for this preprint (which was not certified by peer review) is the author/funder, who has granted bioRxiv a license to display the preprint in perpetuity. It is made available under aCC-BY 4.0 International license.

Figure S3

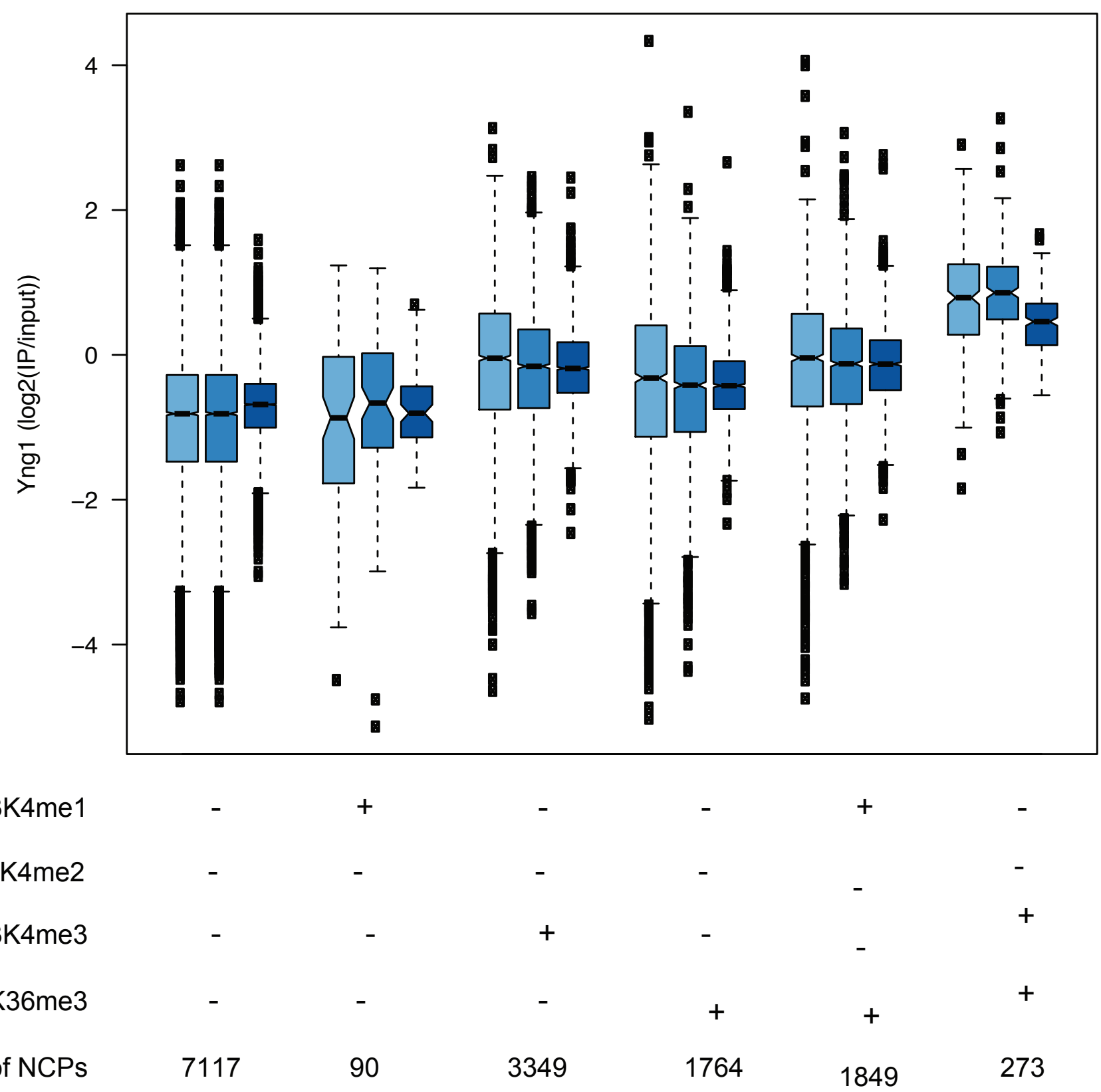


Figure S4

Distance from ATG $(\mathrm{Kb})$
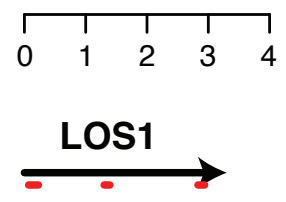

Sas3

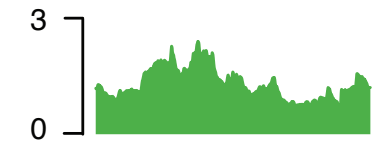

H3K4me1

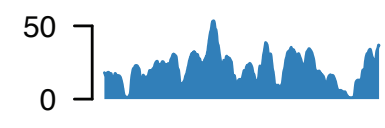

H3K4me2

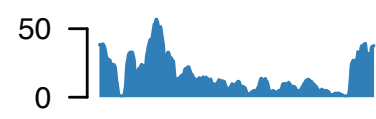

H3K4me3

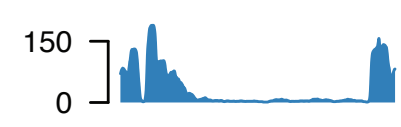

H3K36me3
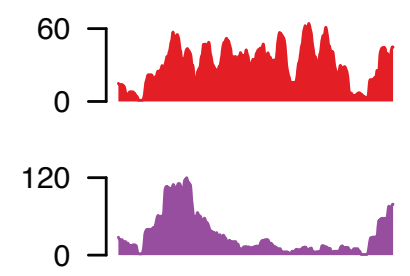

Distance from ATG (Kb)

\begin{tabular}{lllll}
\hline & & & 1 & \\
0 & 1 & 2 & 3 & 4
\end{tabular}
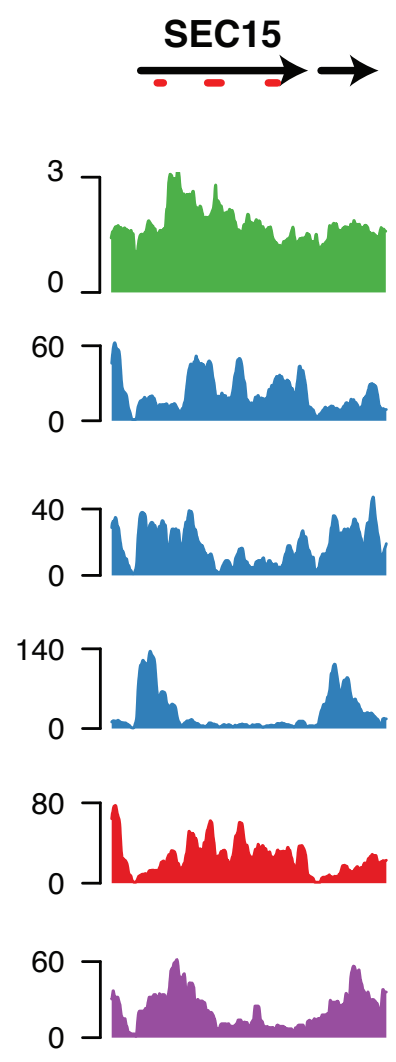

Distance from ATG (Kb)

\begin{tabular}{lllll}
\hline & 1 & & & \\
0 & 1 & 2 & 3 & 4
\end{tabular}
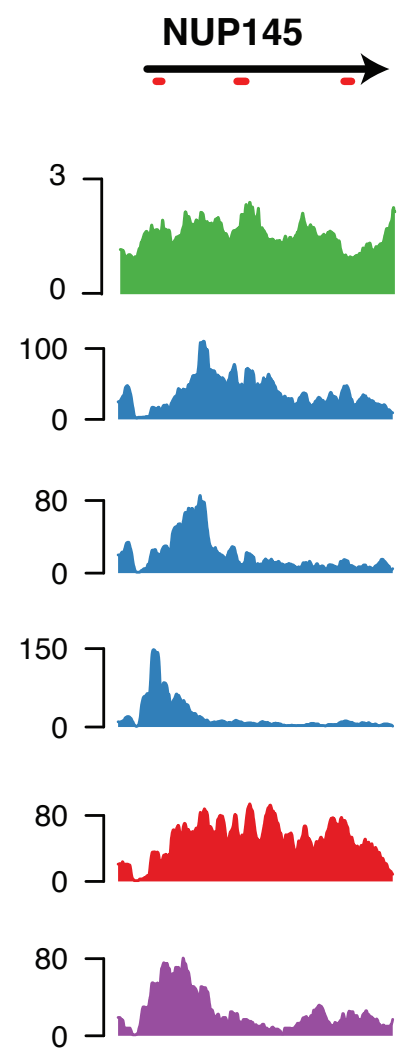

Distance from ATG $(\mathrm{Kb})$

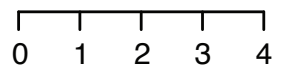
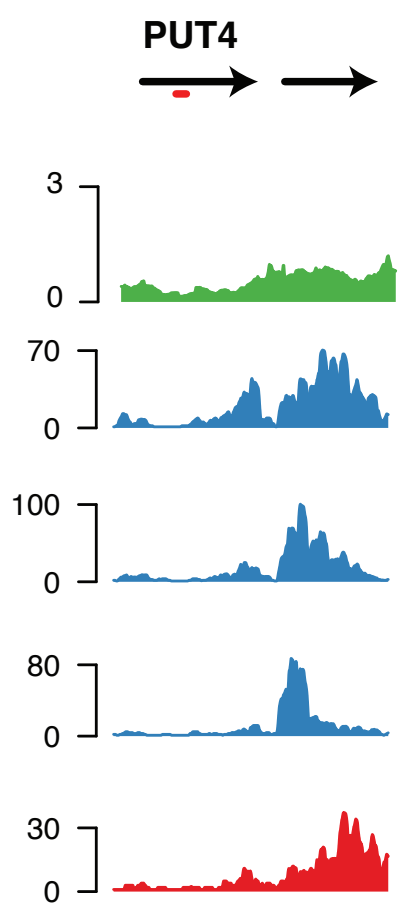

14

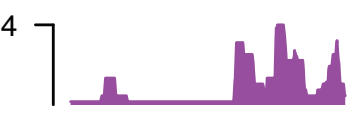


bioRxiv preprint doi: https://doi.org/10.1101/096511; this version posted December 23, 2016. The copyright holder for this preprint (which was not certified by peer review) is the author/funder, who has granted bioRxiv a license to display the preprint in perpetuity. It is made available under aCC-BY 4.0 International license.

Figure S5

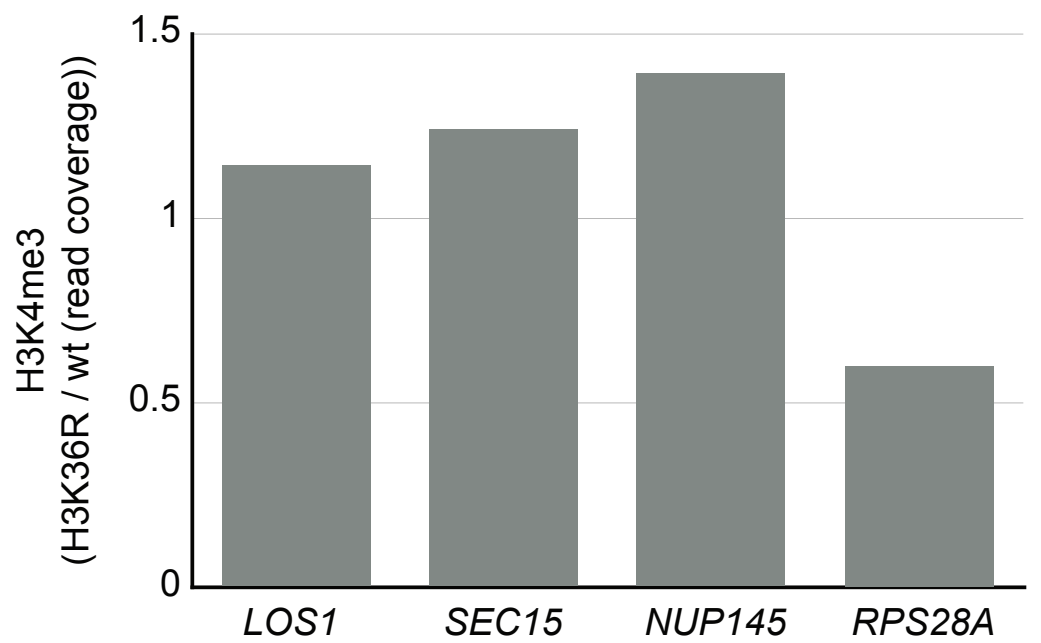


Figure $\mathrm{S} 6$

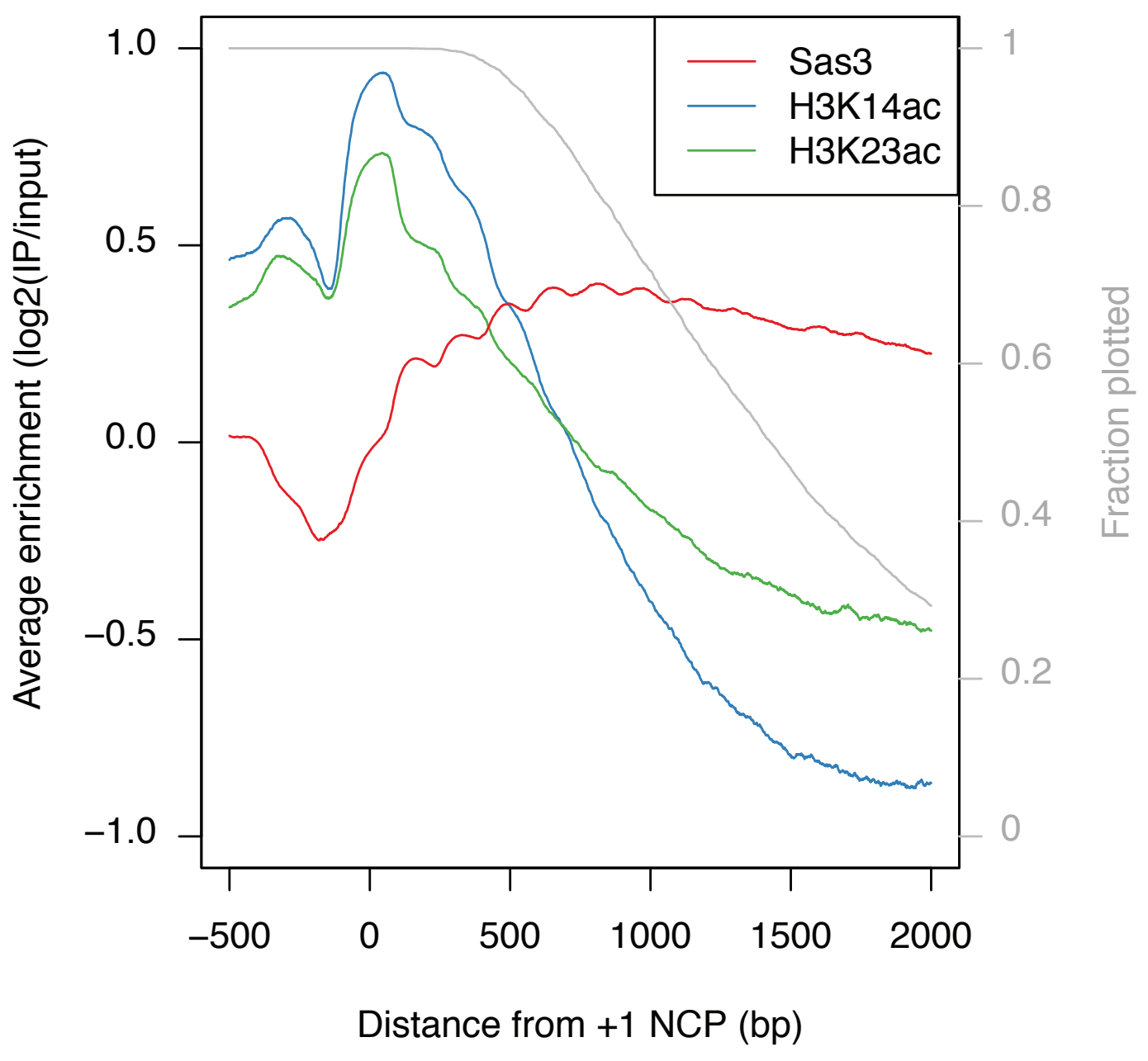


bioRxiv preprint doi: https://doi.org/10.1101/096511; this version posted December 23, 2016. The copyright holder for this preprint (which was not certified by peer review) is the author/funder, who has granted bioRxiv a license to display the preprint in perpetuity. It is made available under aCC-BY 4.0 International license.

Figure $\mathrm{S} 8$
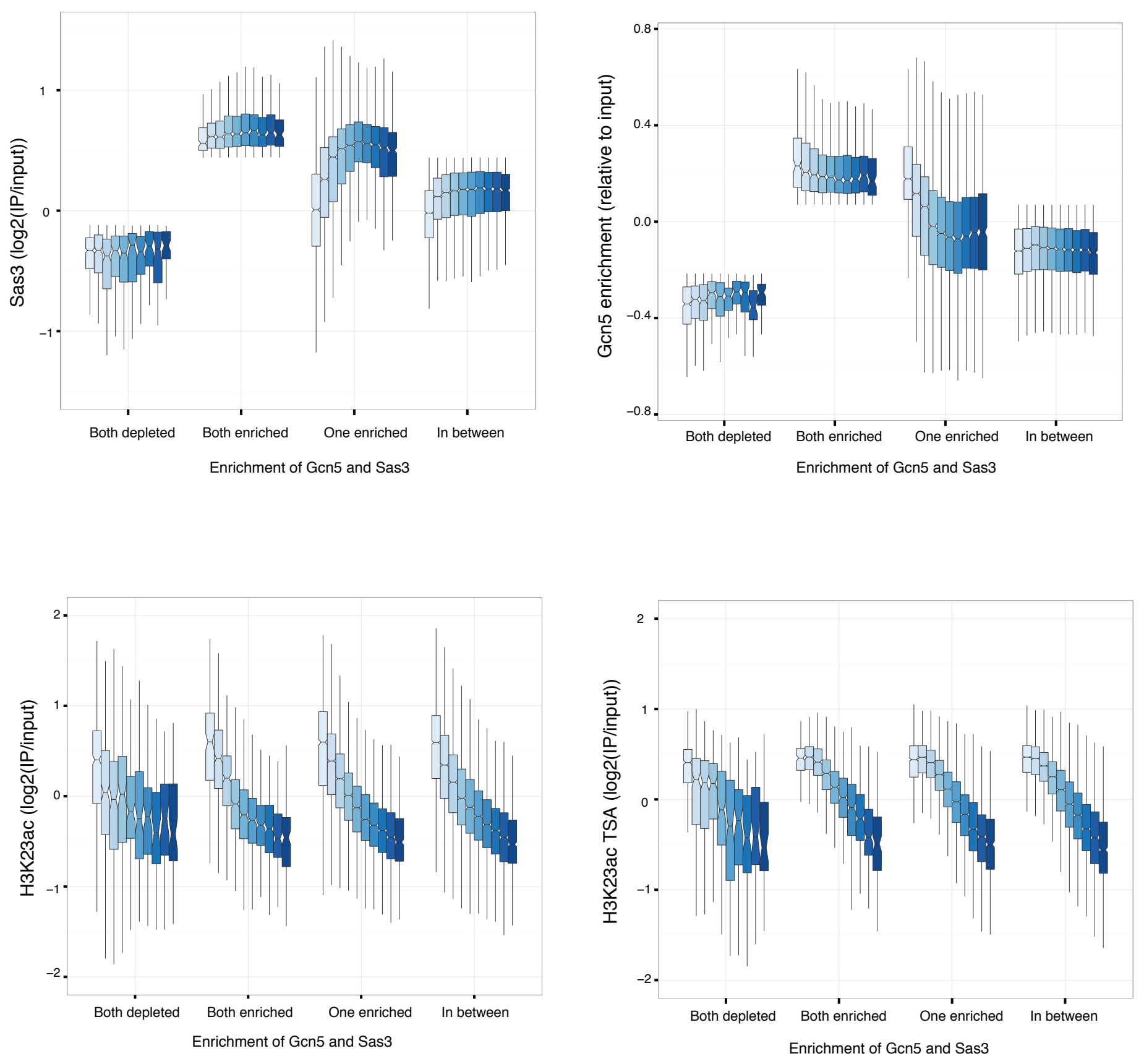